\title{
The evaluation of the anticancer activity of the Biginelli hybrids and pharmacokinetic profiling based on their retention parameters
}

\author{
Jovana Ristovski (Trifunović)a ${ }^{a}$, Renáta Minorics ${ }^{\mathrm{b}}$, Sándor Bartha ${ }^{\mathrm{b}}$, Nenad Jankovićc,*, \\ István Zupkób \\ a University of Novi Sad, Faculty of Medicine, Hajduk Veljkova 3, 21000 Novi Sad, Serbia \\ ${ }^{\mathrm{b}}$ University of Szeged, Faculty of Pharmacy, Department of Pharmacodynamics and Biopharmacy, Eötvös u. 6., H-6720 Szeged, Hungary \\ ' University of Kragujevac, Institute for Information Technologies Kragujevac, Department of Science, Jovana Cvijića bb, Kragujevac, 34000, Serbia
}

\section{A R T I C L E I N F O}

\section{Article history:}

Received 17 December 2021

Accepted 6 January 2022

Available online 8 January 2022

\section{Keywords:}

Biginelli chemistry

Tetrahydropyrimidines

Selectivity index

QSRR model

\begin{abstract}
A B S T R A C T
The present investigation gives an insight into the evaluation and analysis of the anticancer activity of the library of the Biginelli hybrids using the appropriate QSRR approach. Using the RP TLC method retention parameters of tested compounds were obtained and examined to measure of lipophilicity of investigated molecules. The compounds were examined in seven different cancer cell lines and their $\mathrm{IC}_{50}$ and\% of inhibition of cell proliferation at $100 \mu \mathrm{M}$ were established. These experimental values as well as appropriate molecular descriptors are included in QSRR analysis. For this purpose, the variable selection was made, PCA and HCA were carried out, nine MR models were developed and ranked. The quality of the established models was confirmed through internal and external statistical validation. The goal was to define the main differences and similarities between three groups of the tested Biginelli hybrids to -find out which molecular features affect lipophilicity the most and which are crucial for the development of high-quality QSRR models. Tetrahydropyrimidines with butyl (11) and benzyl fragment (19) possess the best anticancer activity and selectivity. Nowadays modern design of an active pharmaceutical ingredient includes specific requirements of rationalization to adapt physicochemical characteristics, pharmacological activity, and safety through structural changes of the molecule. We believe that the developed profile is a step forward in Biginelli chemistry and could be useful in the future synthesis of novel Biginelli-based compounds with significantly improved activities.
\end{abstract}

(C) 2022 Elsevier B.V. All rights reserved.

\section{Introduction}

Pyrimidines act as a potential framework for DNA and RNA, elucidating its importance in drug discovery and development [1]. From the pyrimidines family very important are Biginelli hybrids tetrahydropyrimidines-THPMs (former name-dihydropyrimidines). They were originally synthesized in the XIX century in a multicomponent chemical reaction proposed by Pietro Biginelli [2,3]. Since then, during the optimization of this chemical reaction, conditions were modified several times which resulted in the generation of higher yields, improved enantioselectivities, and inclusion of green methodologies [4]. These scaffolds have attracted imposing interest of medicinal chemists considering their diverse therapeutic and pharmacological properties. Straight forward synthesis of THPMs led to the discovery of many significant products such as antidiabetic, calcium channel blockers, [5] adrenergic receptor antago-

\footnotetext{
* Corresponding author.

E-mail address: nenad.jankovic@kg.ac.rs (N. Janković).
}

nists, anti-inflammatory, antiviral, antioxidant, and anti-SARS THPMs agents [6]. In 1999 Mayer et al. published their work regarding mitotic kinesin inhibitor called „Monastrol” and since then the interest for the anticancer activity of THPMs does not subside [7]. From the beginning of the Biginelli era, there were thousands of Biginelli-like compounds published out to date. Even though the Biginelli reaction was produced a huge number of molecular libraries with broad spectra of activities, among them none were pharmacokinetic profiled.

Lipophilicity represents a physicochemical parameter -that determines the ability of chemical compounds to dissolve in fats, oils, lipids, polar or non-polar solvents, and different body fluids. Specifically, lipophilicity is firmly linked to the behavior of molecules in the biological medium thereby directly regulating its capability for absorption, distribution, metabolism, excretion, and toxicity (ADMET). It has also been found to affect several complex pharmacokinetic parameters such as permeability in the gastrointestinal tract, passage through the blood-brain barrier, penetration through different tissue membranes, interaction with en- 
zymes and efflux pumps, and binding to plasma proteins. Partition coefficient $(P)$ or distribution coefficient $(D)$ represents the ratio of concentrations of a chemical compound in an octanol/water solvent system at equilibrium. Although octanol/water partitioning established itself as the relevant system other solvent systems mixtures have been widely examined as potential alternatives. Considering the importance of lipophilicity, the partition coefficient can be measured experimentally in several different ways: by shakeflask method, employing chromatographic techniques, or using $\mathrm{pH}$ titration [8]. Due to its key importance, some computational approaches have been developed to calculate appropriate $\log P$ values. Various programs rely based on the sum of the contributions $(\pi)$ of the molecular fragments, Abraham's linear free-energy relationship, quantum chemical methods or imply combined approach [8]. Experimentally obtained or calculated $\log P$ values often provide good correlations with ADME properties at least within a congeneric series of compounds. Nevertheless, $\log P$ alone cannot be competent in the prediction of ADME properties for structurally different compounds.

Reversed-phase thin layer chromatography (RP TLC) represents a widely applied chromatographic method that can provide lipophilicity estimation of many compounds with quantitatively comparable, accurate, and reproducible retention data $[9,10]$. Although high-performance liquid chromatography (HPLC) possesses many advantages such as good resolution, speed of analysis, sensitivity, and reproducibility it can be more expensive and complicated in certain cases and can lead to more environmental pollution due to the utilization of huge amount/volume of different solvents and chemicals. Having in mind all aforementioned in this research RP TLC method was applied to estimate retention parameters of Biginelli hybrids.

Estimated lipophilicity parameters are further exploited in several analysis of molecular structure properties relying on chemometric methodologies. Thence, the quantitative structure retention relationship (QSRR) method has been considered adequate to establish a specific strategy and methodology of molecular property predictions. This approach is considered convenient, especially from an overall chemometric perspective because it ensures the best testing of the applicability of specific structural parameters for property description. QSRR approach can be also further employed in the identification of the most suitable molecular descriptors, in the prediction of retention parameters of new analytes, in better understanding of molecular separation under given chromatographic conditions, and for evaluation of different physicochemical properties of examined molecules. [11]

The objective of this work is to investigate the lipophilicity parameters obtained in the RP-TLC chromatography and their possible application in the better rationalization of pharmacological properties of Biginelli hybrids, and, therefore, their applicability in future QSRR studies related to this type of scaffolds. During the research, a comprehensive analysis of selected compounds was performed with the aim to provide a deeper insight into the molecular properties and their biological activities. To reveal similarities/dissimilarities between investigated THPMs multivariate statistical analysis was performed. Through this approach main molecular descriptors that affect lipophilicity were determined. Also, the relationship between chemical structure and anticancer activity of Biginelli hybrids is revealed. For the prediction of anticancer activity of selected Biginelli hybrids appropriate multiple linear regression models (MR) were developed. To compare experimental with the computational approach in estimation of anticancer activity of selected compounds a relatively novel method named as the sum of ranking differences (SRD) was employed. [12] This methodology has been successfully applied for the comparison of obtained MR models with experimentally estimated data and to compare classical with novel chemometric methodologies.
Considering the significance of THPMs and our previous activity in Biginelli chemistry, [13-18] twenty-four compounds were investigated (Table 1 ) in terms of their anticancer activity and pharmacokinetics.

\section{Results and discussion}

\subsection{Chromatographic analysis of selected Biginelli hybrids and its} relationship with molecular lipophilicity

Considering the limitations of normal phase chromatography systems and analyzing the lipophilic nature and chemical structure of selected Biginelli hybrids our analytes were examined using RP-C18 thin-layer plates. Two types of mobile phases were applied, one phase was based on $\mathrm{MeOH}$ and the second one on $\mathrm{MeCN}$, each with the same ratio of organic solvent and water $(\Phi(\mathrm{MeCN} / \mathrm{MeOH})=0.5-0.7 \mathrm{v} / \mathrm{v})$. In comparison with normal-phase systems, much better retention behavior was noted using reversedphase systems. It was probably due to chemical nature of selected compounds and their interactions with polar stationary phase. The group of Biginelli hybrids studied in this work included molecules with similar structures, sizes, and polarities, so it was expected that they have similar chromatographic behavior. Thus, the fraction of $\mathrm{MeOH}$ and $\mathrm{MeCN}$, for which a linear range was obtained for retention parameters, ranged between 50 and $70 \%$ and an increment of $5 \%$ was applied to achieve the five specified concentrations. The $R_{M}$ values decreased linearly, with an increasing concentration of $\mathrm{MeOH} / \mathrm{MeCN}$ in the mobile phase. These values extrapolated to $0 \%$ of $\mathrm{MeOH} / \mathrm{MeCN}$ gave the relative lipophilicity parameter $\left(R_{M}{ }^{0}\right)$ values, which characterize the partitioning between the non-polar stationary and polar mobile phases. After extrapolation of $R_{M}$ values, obtained $R_{M}{ }^{0}$ values represent retention of the analyzed compounds in pure water. The $\mathrm{R}_{\mathrm{M}}{ }^{0}$ values reflect lipophilicity of examined molecules and the slope (b) is related to hydrophilic surface area of these compounds. The established linear relationship between the relative lipophilicity parameter $\left(R_{M}{ }^{0}\right)$ and the slope (b) (Fig 1.) ensured us to spot congeneric compound subclasses in the set of studied Biginelli hybrids. Examined THPMs molecules of twenty-four hybrids (Table 1) are separated into three groups according to their fragments at C5 position: ethyl ester (I group), methyl ester (II group) and acetyl (III group). Compounds possess similar log $\mathrm{P}$ values but differ in calculated ADME and experimentally obtained anticancer activities. The difference in molar mass (220.23 - 455.35) and solvent accessible surface area of all hydrophobic atoms (58.64 - 112.20) indicate the presence of diverse substituents which could be the reason for various biological effects of examined molecules.

The strong linear dependence of retention parameters through the $\mathrm{MeOH} / \mathrm{MeCN}$ fraction with the calculated milogP values was demonstrated by the values of $\mathrm{R}^{2}$ of 0.95 and 0.96 (Table S1, Fig. 1a and $1 \mathrm{~b})$. Also, correlation between retention constants $\left(\mathrm{R}_{\mathrm{M}}{ }^{0}\right)$ and slope (b) is statistically significant with $\mathrm{R}^{2}$ values of 0.9518 (Fig. 1c) and 0.9533 (Fig. 1d) respectively. Furthermore, considering the correlation between $\mathrm{R}_{\mathrm{M}}{ }^{0}$ parameters estimated by using both mobile phases and $\log \mathrm{D} \mathrm{pH}=7.4\left(R^{2} \mathrm{MeOH} / \mathrm{H}_{2} \mathrm{O}\right.$ is 0.9185 (Fig. $\left.1 \mathrm{e}\right)$ and $\mathrm{R}^{2} \mathrm{MeCN} / \mathrm{H}_{2} \mathrm{O}$ is 0.9013 (Fig. 1f) as well as in the case with miLogP can be indicated that $\mathrm{R}_{\mathrm{M}}{ }^{0}$ values of $\mathrm{MeOH} / \mathrm{H}_{2} \mathrm{O}$ and $\mathrm{MeCN} / \mathrm{H}_{2} \mathrm{O}$ could be applied as chromatographic lipophilicity parameters of investigated Biginelli hybrids.

In this study, two chromatographic systems were examined. The first is based on methanol, the second is based on acetonitrile with the same ratio of water. Using $\mathrm{MeOH}$ as polar protic solvent obtained lipophilicity parameters of $\mathrm{R}_{\mathrm{M}}{ }^{0}$ values are higher than in the case when $\mathrm{MeCN}$ as polar aprotic solvent was applied. The highest number of spots and separation efficiency was observed by using acetonitrile-water with $60 \%$ of $\mathrm{MeCN}$. From the qualitative point 
Table 1

The chemical structures of the studied THPMs (1-24).<smiles>[R]C1=C(C)NC(c2cc([R])c([R2])c([R])c2)NC1[R]</smiles>

1-16, 18-24<smiles>[R]C1=C(C)NC([R6])NC1c1ccco1</smiles>

17

\begin{tabular}{|c|c|c|c|c|c|c|}
\hline Compound & $\mathrm{R} 1$ & $\mathrm{R} 2$ & R3 & $\mathrm{R} 4$ & R5 & Group \\
\hline 1 & $\mathrm{COOCH}_{2} \mathrm{CH}_{3}$ & $\mathrm{H}$ & $\mathrm{H}$ & $\mathrm{H}$ & $\mathrm{S}$ & I \\
\hline 2 & $\mathrm{COOCH}_{2} \mathrm{CH}_{3}$ & $\mathrm{OCH}_{2} \mathrm{CH}=\mathrm{CHCH}_{3}$ & $\mathrm{OCH}_{3}$ & $\mathrm{H}$ & 0 & I \\
\hline 3 & $\mathrm{COOCH}_{2} \mathrm{CH}_{3}$ & $\mathrm{OCH}_{2} \mathrm{C}\left(\mathrm{CH}_{3}\right)=\mathrm{CH}_{2}$ & $\mathrm{OCH}_{3}$ & $\mathrm{H}$ & 0 & I \\
\hline 4 & $\mathrm{COOCH}_{2} \mathrm{CH}_{3}$ & $\mathrm{O}\left(\mathrm{CH}_{2}\right)_{4} \mathrm{Br}$ & $\mathrm{OCH}_{3}$ & $\mathrm{H}$ & 0 & I \\
\hline 5 & $\mathrm{COOCH}_{2} \mathrm{CH}_{3}$ & $\mathrm{O}\left(\mathrm{CH}_{2}\right)_{5} \mathrm{Br}$ & $\mathrm{OCH}_{3}$ & $\mathrm{H}$ & 0 & I \\
\hline 6 & $\mathrm{COCH}_{3}$ & $\mathrm{OH}$ & $\mathrm{OCH}_{3}$ & $\mathrm{H}$ & 0 & III \\
\hline 7 & $\mathrm{COOCH}_{2} \mathrm{CH}_{3}$ & $\mathrm{OCH}\left(\mathrm{CH}_{3}\right)_{2}$ & $\mathrm{OCH}_{3}$ & $\mathrm{H}$ & $\mathrm{S}$ & I \\
\hline 8 & $\mathrm{COOCH}_{3}$ & $\mathrm{O}\left(\mathrm{CH}_{2}\right)_{2} \mathrm{CH}_{3}$ & $\mathrm{OCH}_{3}$ & $\mathrm{H}$ & 0 & II \\
\hline 9 & $\mathrm{COOCH}_{3}$ & $\mathrm{OCH}_{2} \mathrm{CH}=\mathrm{CHCH}_{3}$ & $\mathrm{OCH}_{3}$ & $\mathrm{H}$ & 0 & II \\
\hline 10 & $\mathrm{COOCH}_{3}$ & $\mathrm{OCH}_{2} \mathrm{C}\left(\mathrm{CH}_{3}\right)=\mathrm{CH}_{2}$ & $\mathrm{OCH}_{3}$ & $\mathrm{H}$ & 0 & II \\
\hline 11 & $\mathrm{COOCH}_{3}$ & $\mathrm{O}\left(\mathrm{CH}_{2}\right)_{3} \mathrm{CH}_{3}$ & $\mathrm{OCH}_{3}$ & $\mathrm{H}$ & 0 & II \\
\hline 12 & $\mathrm{COOCH}_{3}$ & $\mathrm{O}\left(\mathrm{CH}_{2}\right)_{3} \mathrm{Br}$ & $\mathrm{OCH}_{3}$ & $\mathrm{H}$ & 0 & II \\
\hline 13 & $\mathrm{COOCH}_{3}$ & $\mathrm{OCH}_{2} \mathrm{CH}=\mathrm{CH}_{2}$ & $\mathrm{OCH}_{3}$ & $\mathrm{H}$ & 0 & II \\
\hline 14 & $\mathrm{COOCH}_{3}$ & $\mathrm{OCH}_{3}$ & $\mathrm{OCH}_{3}$ & $\mathrm{H}$ & 0 & II \\
\hline 15 & $\mathrm{COOCH}_{3}$ & $\mathrm{OCH}_{2} \mathrm{CH}_{3}$ & $\mathrm{OCH}_{3}$ & $\mathrm{H}$ & 0 & II \\
\hline 16 & $\mathrm{COOCH}_{3}$ & $\mathrm{OCH}_{2} \mathrm{COOCH}_{2} \mathrm{CH}_{3}$ & $\mathrm{OCH}_{3}$ & $\mathrm{H}$ & 0 & II \\
\hline 17 & $\mathrm{COCH}_{3}$ & - & - & - & 0 & III \\
\hline 18 & $\mathrm{COOCH}_{3}$ & $\mathrm{H}$ & $\mathrm{H}$ & $\mathrm{H}$ & 0 & II \\
\hline 19 & $\mathrm{COOCH}_{3}$ & $\mathrm{OCH}_{2} \mathrm{Ph}$ & $\mathrm{OCH}_{3}$ & $\mathrm{H}$ & 0 & II \\
\hline 20 & $\mathrm{COCH}_{3}$ & $\mathrm{NO}_{2}$ & $\mathrm{H}$ & $\mathrm{H}$ & 0 & III \\
\hline 21 & $\mathrm{COOCH}_{2} \mathrm{CH}_{3}$ & $\mathrm{OH}$ & $\mathrm{OCH}_{3}$ & $\mathrm{H}$ & 0 & I \\
\hline 22 & $\mathrm{COOCH}_{2} \mathrm{CH}_{3}$ & $\mathrm{OCH}_{3}$ & $\mathrm{OCH}_{3}$ & $\mathrm{H}$ & 0 & I \\
\hline 23 & $\mathrm{COOCH}_{3}$ & $\mathrm{OCH}_{3}$ & $\mathrm{OCH}_{3}$ & $\mathrm{OCH}_{3}$ & 0 & II \\
\hline 24 & $\mathrm{COOCH}_{3}$ & $\mathrm{Cl}$ & $\mathrm{H}$ & $\mathrm{H}$ & 0 & II \\
\hline
\end{tabular}

of view, simple RP-C18 plates developed in a mobile phase containing $\mathrm{MeCN} / \mathrm{H}_{2} \mathrm{O}(\Phi(\mathrm{MeCN})=0.6)$ are sufficient for separation of all tested Biginelli hybrids. This method could be particularly interesting as an identification step in the quality control during the synthesis of different Biginelli hybrids. Modifications of the chemical structure of Biginelli hybrids by introducing different groups that influence lipophilicity can lead to change of ADMET properties that are also affected by lipophilicity. Because lipophilicity can be experimentally measured as well as calculated it allows combining theoretical and experimental approaches in comparison and testing of these methods and improvement of future steps in the design of novel Biginelli hybrids.

\subsection{Multivariate statistical analysis}

In HCA analysis are included experimentally obtained retention parameters as well as molecular descriptors related to ADME characteristics of studied molecules to reveal similarities and dissimilarities between three groups of THPMs. In addition to the implementation of dendrograms, results are also presented using heat maps where are the lowest values depicted in dark red/blue and the highest in gray/red color (Fig. 2).

Clustering of compounds regarding retention parameters indicates the good separation between molecules with a very small number of overlaps between them (Fig. 2a). Group I is well separated within the first cluster with compound 21 that represents exception and belongs to the second cluster. The reason for this could be in similarity of its retention parameters to the second group of molecules. This compound according to its chemical structure belongs to group I but considering chromatographic behavior it is a member of group II. As a part of second cluster, it can be spotted third group of examined Biginelli hybrids which possess the lowest values of retention parameters. Compound $\mathbf{1 7}$ of group III can be marked as outlier, probably due to presence of furyl group which makes it specific among the studied Biginelli hybrids. The second group of studied molecules is deployed within both clusters considering its chromatographic parameters which are in the middle of the scale of presented data values.

After performing HCA analysis on the data set which includes retention parameters, physicochemical descriptors, and ADME descriptors, clustering results (Fig. 2b) have shown certain differences from the results obtained in HCA when only retention parameters were included (Fig 2a). From group I of compounds molecules $\mathbf{1}$ and $\mathbf{2 1}$ are placed in different cluster from the other members of this group. The reason could be due to specific pharmacokinetic properties which are more like the compounds from the second cluster. Compounds that belong to group III are arranged in the second cluster which includes $\mathbf{1 7}$ molecules that possess similar 
a)

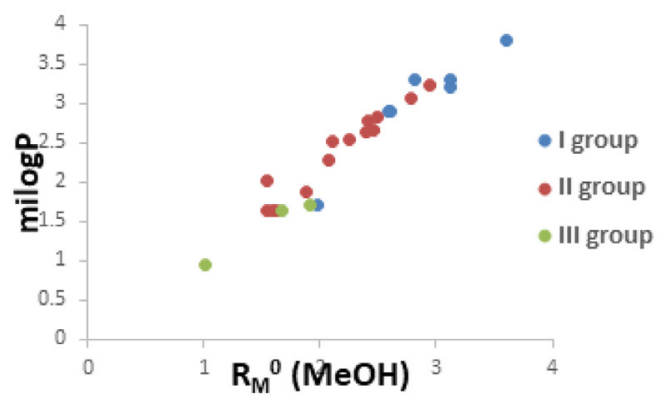

c)

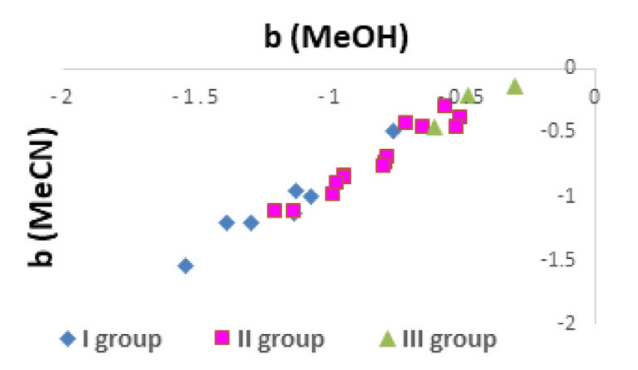

e)

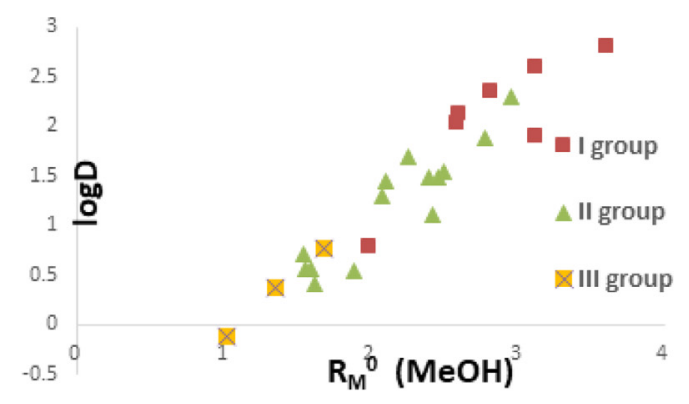

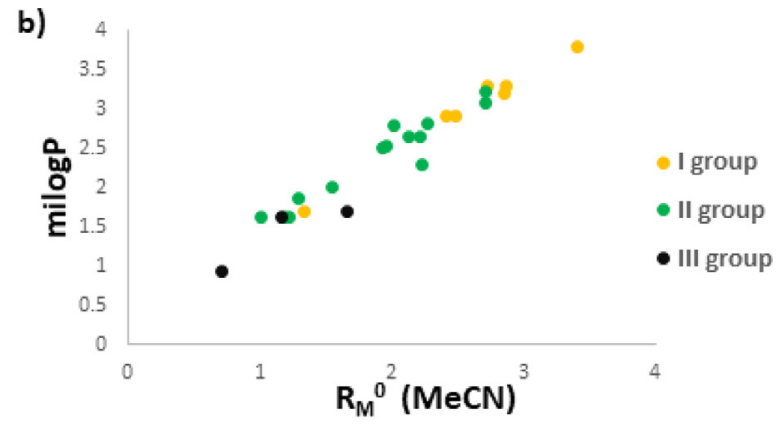

d)

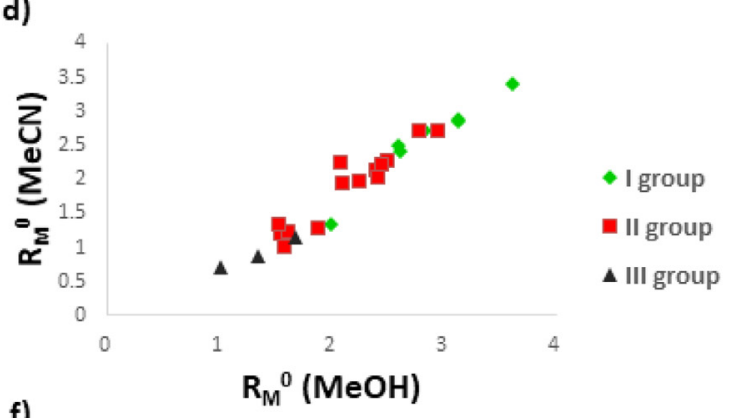

f)

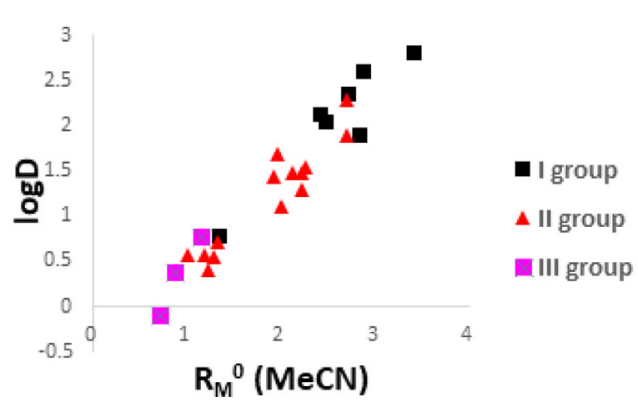

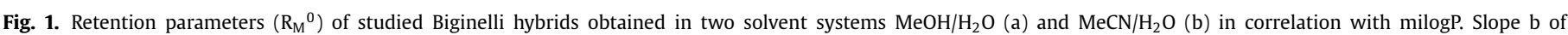

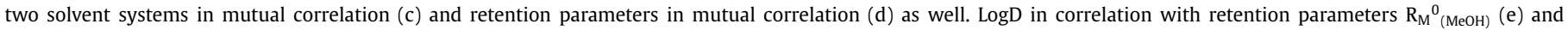
$\mathrm{R}_{\mathrm{M}} 0_{\text {(MeCN) }}$ (f).

ADME characteristics. Molecules with the best antitumor activity belong to this cluster and show significant similarity in physicochemical and pharmacokinetic aspects. Appropriate pharmacokinetic profiles of investigated molecules are of crucial importance for future evaluation of their possible therapeutic application. Considering this fact profound HCA analysis enables insight into similarities/dissimilarities between compounds regarding their pharmacological features (Fig. 2b). Molecules 11, 12, and 19 which are labeled as the most potent candidates possess also satisfying pharmacokinetic properties and will be subjected to further studies to examine their therapeutic potential.

In order to reduce the dimensionality of our data sets Principal component analysis was performed and two components model was acquired with $94 \%$ of the total variance. Extracted Eigenvectors and Eigenvalues of the correlation matrix are presented in Electronic Supplementary Information (ESI) (Table S6 and S7). The biplot represents both the loadings and the score for two selected components in parallel. Investigated Biginelli hybrids were analyzed in the context of the lipophilicity and chromatographic behavior (Fig 3a) calculated physicochemical descriptors (Fig. 3b) and pharmacological properties (Fig 3c). The biplot presented in Fig. 3a suggests that along the Principal Component 1 axis, which represents $91.11 \%$ of total variability, group I shows higher lipophilicity values than group III which is located on the opposite side of Principal Component 1 axis. Alongside the Principal Component 2 axis, which covers $2.98 \%$ of total variability, small grouping of the compounds of the II series can be spotted. It can be observed that retention parameters $\left(\mathrm{R}_{\mathrm{M}}{ }^{0} \mathrm{MeOH}\right.$ and $\left.\mathrm{b} \mathrm{MeCN}\right)$ strongly influence Principal Component 2 as it is presented in the biplot (Fig. 3a). Retention parameters also have significant impact on Principal Component 1 , however, it is evident that the separation of the series II along Principal Component 2 is predominantly based on $\mathrm{b}(\mathrm{MeCN})$ values.

The second PCA model is based on the physicochemical molecular properties of investigated compounds. This established model covers $92.13 \%$ of the total variability. The biplot presented in Fig. 3b suggests the adequate distribution of the Biginelli hybrids between the PCA 1 and PCA 2 axis. The details regarding second PCA model are presented in Tables S7 and S8. Similarly, to the previous PCA model Group I of examined molecules is placed on the positive side and group III on the negative side of PCA 1 axis. All included physicochemical parameters express strong influence on the PCA1, but on the other side, ASA minus and HLB strongly affected PCA2 and show less influence on PCA1. Compound 1 shows similar physicochemical characteristics with group III of compounds which can be a consequence of the presented sulfur atom inside this molecule. Compound $\mathbf{2 4}$ from II group also possesses similar physicochemical effects with group III which can also be due to the presence of chlorine atom in the molecule. 


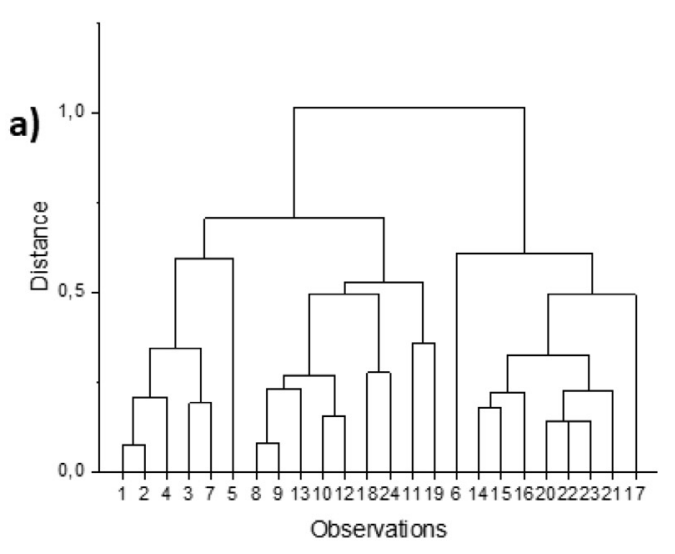

b)

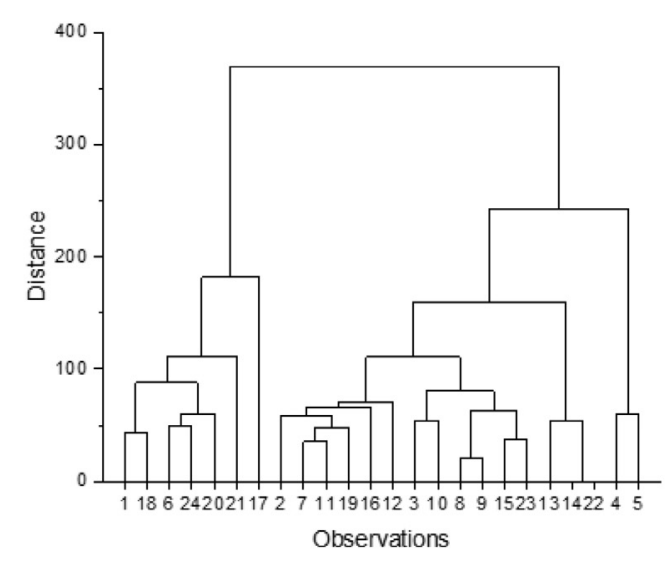

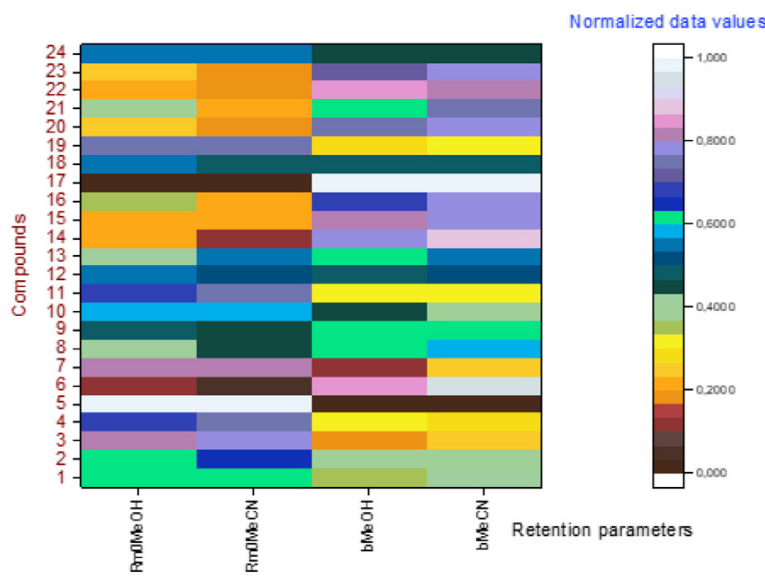

Normalized data values

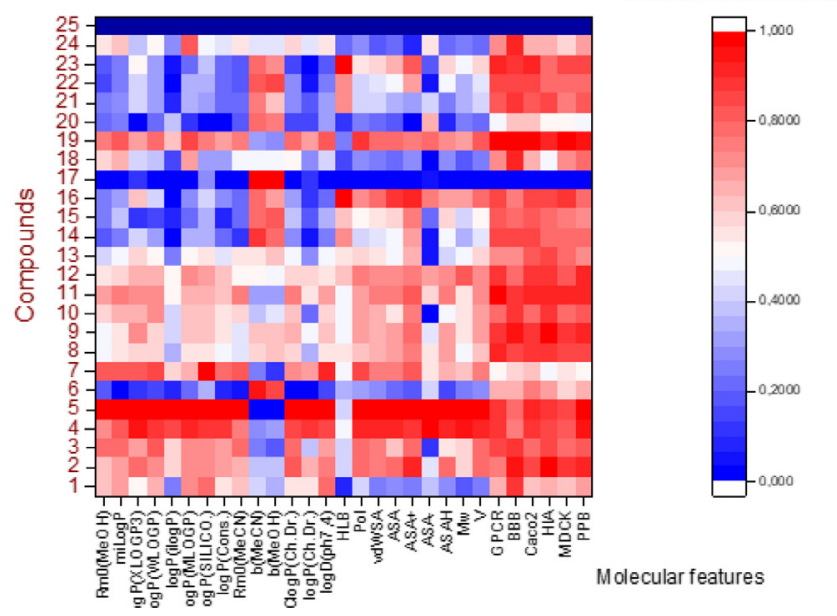

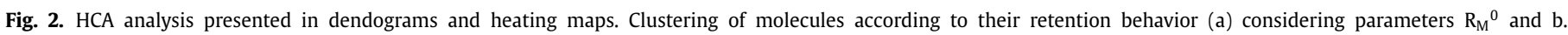
Clustering of molecules according to their retention parameters, calculated log P values, physicochemical descriptors and ADME descriptors (b).

In order to investigate relations between experimentally obtained (\%INH) values of analyzed compounds in seven different cell lines, retention parameters, and calculated pharmacokinetic descriptors the third PCA analysis was performed (Fig. 3c). Details regarding the third PCA model can, also, be found in ESI (Tables S10 and S11). This PCA model explains $79.64 \%$ of the total variance, with the two significant PCA. Analyzing biplot as a result of PCA, similarities, or dissimilarities among the data can be observed. All experimentally obtained data (\%INH values and retention parameters) possess positive influence on PC1. Pharmacokinetic descriptors HIA, PPB, and Caco2 show also positive influence on PC1 and they are in good correlation with experimentally obtained data. The results of the PCA analysis suggest which molecular descriptors are suitable to be included in further chemometrics analysis and which should not be considered during the development of appropriate QSRR models.

The results of the multivariate analysis indicate which molecular properties of studied Biginelli pyrimidines should be particularly included in further chemometric analysis. Furthermore, the data from HCA and PCA analysis emphasize specific molecular descriptors which are responsible for the main differences between examined compounds. Structural changes of the molecules can affect specific molecular properties e.g. inductive and steric effects and have also an impact on the chromatographic behavior of investigated molecules. Aliphatic and phenyl groups are voluminous and because of the steric effect, they hinder access of donor atoms to silanol groups on the stationary phase. According to HCA and PCA analysis, it could be noted that the grouping of investigated molecules into three series is particularly based on the type of substituents attached to THPM moiety. Observed clustering of Biginelli hybrids along PC1 axis in the context of RP TLC shows expressed grouping of molecules in relation to the presented substituents with the aim to favor hydrophobic interactions in this chromatographic system.

\subsection{QSRR modeling of anticancer and retention behavior of Biginelli hybrids by MR approach}

In establishing QSRR model Multiple linear regression (MR) analysis was applied. Performed MR is based on a variety of calculated molecular descriptors selected by the stepwise variable subset selection procedure. The stepwise selection was utilized to develop a regression equation for twenty-four compounds and molecular descriptors are chosen based on their impact on the retention parameters of investigated molecules under the applied chromatographic conditions. The regression equations included three parameters: distribution coefficient $(\log \mathrm{D}, \mathrm{pH} 7.4)$, the solvent accessible surface area of all hydrophobic atoms (ASA$\mathrm{H}$ ), and molecular weight (Mw) of the examined compounds. Modeling of retention parameters of these molecules as a function of the theoretically derived descriptors was established by MR. MR models are represented by equations:

$$
\begin{gathered}
\mathrm{MR} 1: R_{\mathrm{M}(\mathrm{MeOH})}^{0}=0.9677( \pm 0.2893)+0.7363( \pm 0.0768) \\
\log \mathrm{D}-0.0014( \pm 0.0011) \mathrm{ASA}-\mathrm{H}+0.0029( \pm 0.0019) \mathrm{Mw}
\end{gathered}
$$


a)
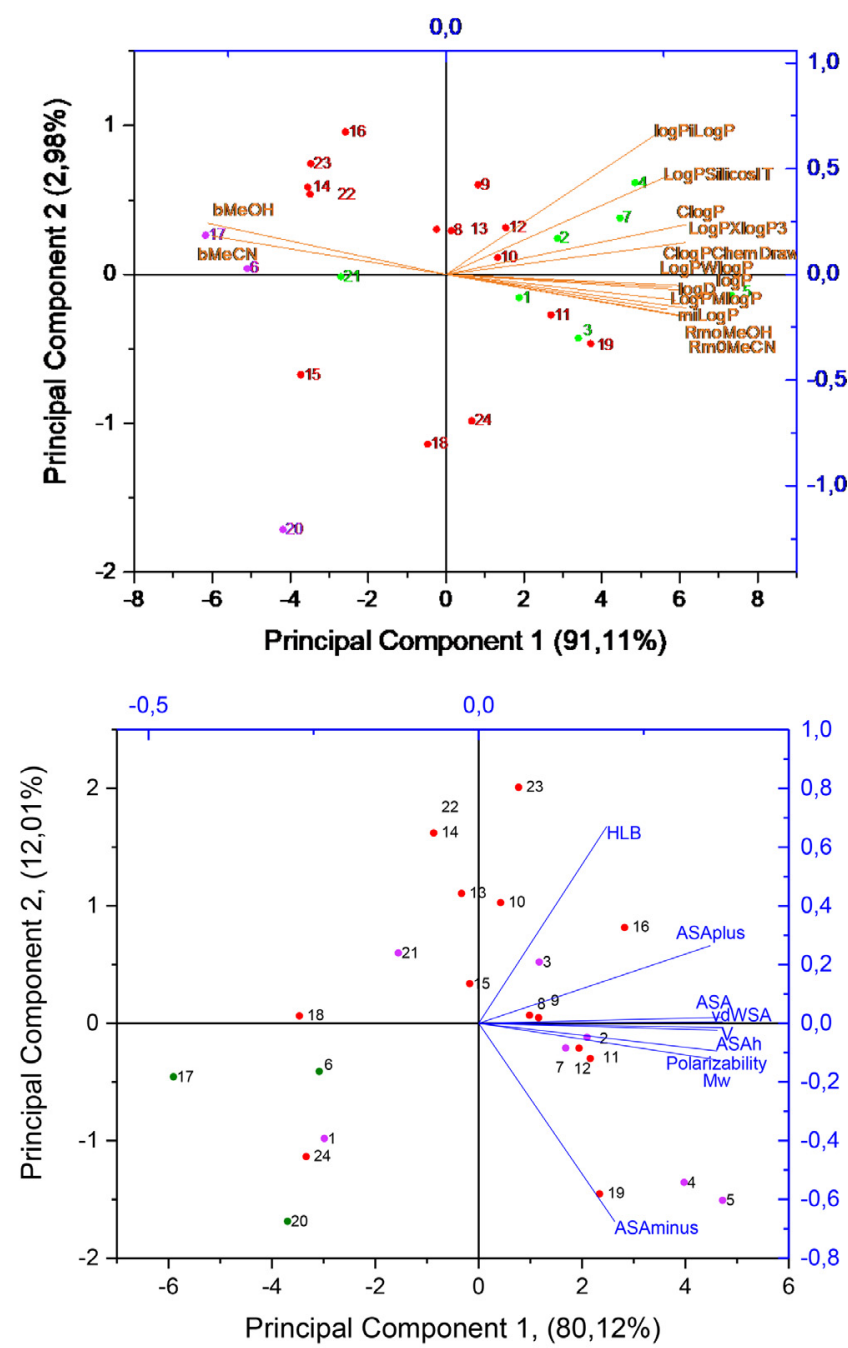

c)

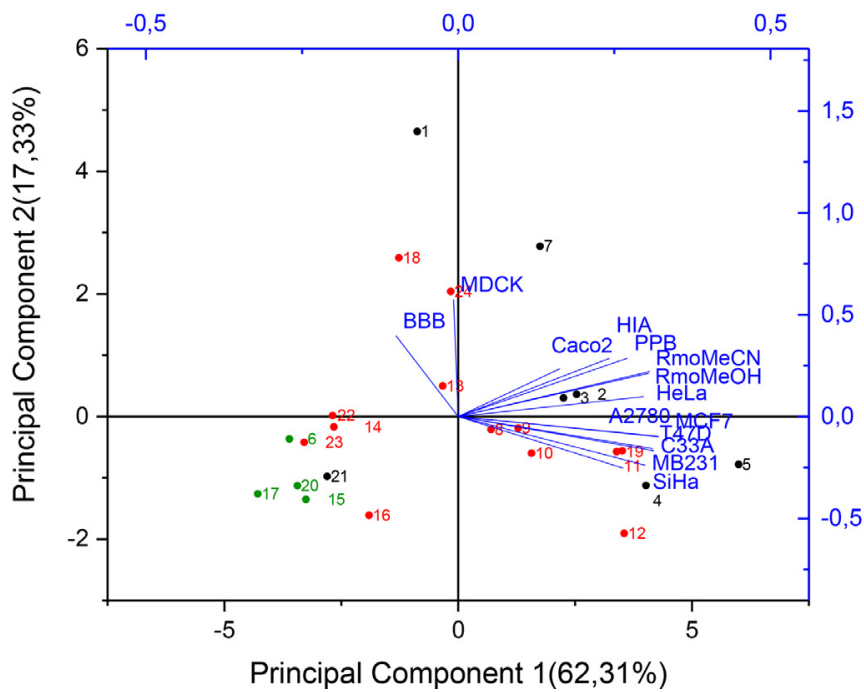

Fig. 3. Results of PCA analysis for first two components considering a) retention parameters and calculated $\log \mathrm{P}$ values b) physicochemical descriptors, c) retention parameters,\%INH and pharmacokinetic descriptors. .
Table 2

Results of statistical analysis for MR1 and MR2 models.

\begin{tabular}{ll}
\hline MR1 & MR2 \\
$\mathrm{R}^{2}=0.90$ & $\mathrm{R}^{2}=0.904$ \\
$\mathrm{R}^{2}$ Adj. $=0.885$ & $\mathrm{R}^{2}$ Adj. $=0.89$ \\
$F=60.294$ & $F=62.933$ \\
$\operatorname{VIF}(\log D)=1.919$ & $\operatorname{VIF}(\log D)=1.919$ \\
$\operatorname{VIF}($ ASA-H $)=7.354$ & $\operatorname{VIF}($ ASA-H $)=7.354$ \\
$\operatorname{VIF}(M w)=6.771$ & $\operatorname{VIF}(M w)=6.771$ \\
\hline
\end{tabular}

Table 3

Cross validation summary for MR1 and MR2 models.

\begin{tabular}{lll}
\hline $\mathrm{CV}$ & -0.008 & 0.08 \\
PRESS & -0.2 & 0.2 \\
$\mathrm{SS}_{\mathrm{T}}$ & 9.21 & 12.52 \\
$\mathrm{R}^{2}$ (pred.) & 1.02 & 0.98 \\
\hline
\end{tabular}

Table 4

Variable importance projection-VIP values of MR1 and MR2 models.

\begin{tabular}{lll}
\hline & MR1 & MR2 \\
\hline $\log$ D & 1.2 & 1.2 \\
ASA-H & 0.9 & 0.9 \\
Mw & 0.9 & 0.8 \\
\hline
\end{tabular}

$\mathrm{MR} 2: R_{\mathrm{M}(\mathrm{MeCN})}^{0}=0.634( \pm 0.33)+0.864( \pm 0.087)$

$\log \mathrm{D}-0.0009( \pm 0.0013) \mathrm{ASA}-\mathrm{H}+0.00178( \pm 0.0022) \mathrm{Mw}$

Internal and external validation was performed to develop statistically valid models for the retention parameters prediction. To conduct external validation data set was divided into two sets, calibration set that includes nineteen samples and an external test set with five samples. Obtained results indicate strong a correlation between retention parameters and selected molecular descriptors. Predicted retention values are in good agreement with experimentally obtained (Fig. 4). This is confirmed by determination coefficients of the established modes, intercept values around 0 and slope values around 1. The statistical parameters of the MR1 and MR2 models are presented in Table 2. Established MR models show significantly high correlation coefficients and low variance inflation factor values (VIF). The intercorrelation of the selected molecular descriptors was examined and obtained VIF parameters are lower than ten which exclude the multicollinearity phenomenon. F-test values show good fitting of the MR models to a data set.

In this work leave-one-out, cross-validation method was applied to estimate the performance of established MR models. It includes a single observation as validation data and leaves the remains as training data. Cross-validation error (CV), predicted residual error sum of squares (PRESS), the sum of squares total (SST), and predictive $\mathrm{R}$-square $\left(\mathrm{R}^{2}\right.$ (pred.)) are presented in Table 3. Predictive R-square is a better measure of the predictive power of a regression model than R-square. Variable importance in projection (VIP) (Table 4) value estimates the importance of each variable. Variable is considered as important if its VIP value is greater than 0.8 .

To develop QSRR models with significant prediction ability molecular descriptors were selected as previously described. Experimentally obtained retention parameters are in good correlation $\left(R^{2} \geq 50\right)$ with experimentally obtained anticancer activities of Biginelli hybrids. Additionally, the same molecular descriptors that are included in MR 1 and MR2 were used for development of MR4-9 models. Only in MR3 model design HIA and PPB\% descriptors were 

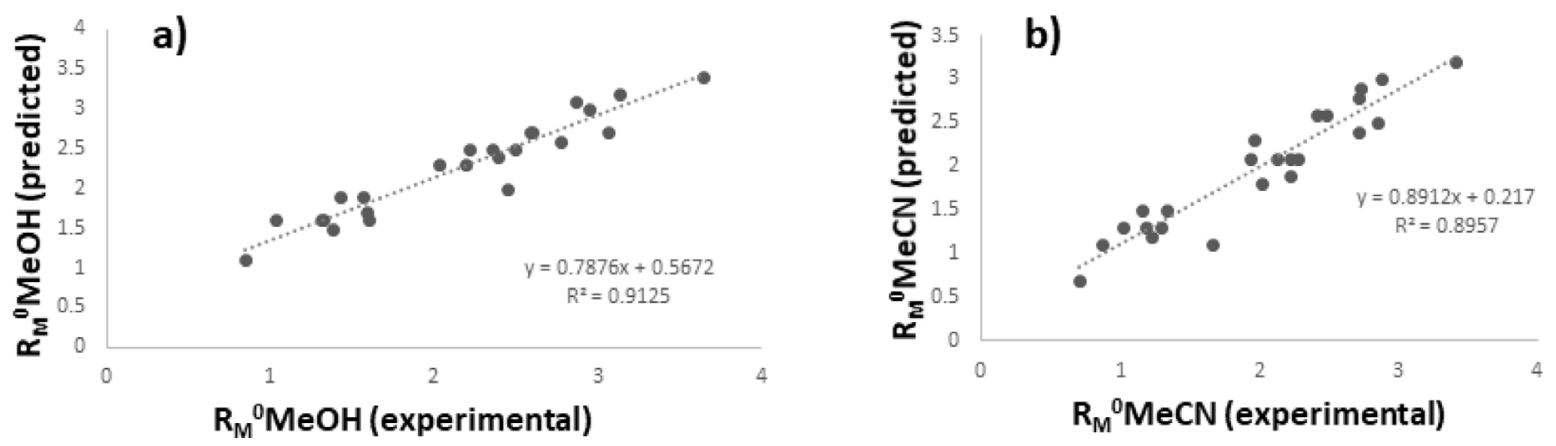

Fig. 4. The correlation between experimentally obtained retention values and predicted retention values using a) MR1 and b) MR2 model.

Table 5

Established MR3-9 models.

\begin{tabular}{|c|c|}
\hline \multicolumn{2}{|c|}{ Multiple Linear Regression Models } \\
\hline MR3 & $\mathrm{IC}_{50}(\mathrm{HeLa})=20.028( \pm 79.498)+16.512( \pm 9.18) \mathrm{R}_{\mathrm{M}}{ }_{(\mathrm{MeOH})}-0.526( \pm 0.94) \mathrm{HIA}+0.674( \pm 0.372) \mathrm{PPB}$ \\
\hline MR4 & $\mathrm{IC}_{50}(\mathrm{SiHa})=-66.395( \pm 16.539)+0.514( \pm 4.934) \mathrm{R}_{\mathrm{M}}^{0}(\mathrm{MeOH})+0.039( \pm 0.07) \mathrm{ASAH}+0.218( \pm 0.121) \mathrm{Mw}$ \\
\hline MR5 & $\mathrm{IC}_{50}(\mathrm{~A} 2780)=-110.9( \pm 26.251)+22.523( \pm 7.832) \mathrm{R}_{\mathrm{M}}^{0}(\mathrm{MeOH})+0.046( \pm 0.112) \mathrm{ASAH}+0.224( \pm 0.192) \mathrm{Mw}$ \\
\hline MR6 & $\mathrm{IC}_{50}(\mathrm{C} 33 \mathrm{~A})=-89.179( \pm 23.558)+14.763( \pm 7.028) \mathrm{R}_{\mathrm{M}}^{0}(\mathrm{MeOH})+0.024( \pm 0.1) \mathrm{ASAH}+0.25( \pm 0.17) \mathrm{Mw}$ \\
\hline MR7 & $\mathrm{IC}_{50}(\mathrm{MCF})=-79.711( \pm 15.350)+14.926( \pm 4.579) \mathrm{R}_{\mathrm{M}}{ }_{(\mathrm{MeOH})}+0.0665( \pm 0.065) \mathrm{ASAH}+0.181( \pm 0.112) \mathrm{Mw}$ \\
\hline MR8 & $\mathrm{IC}_{50}(\mathrm{~T} 47 \mathrm{D})=-75.179( \pm 15.723)+10.8( \pm 4.69) \mathrm{R}_{\mathrm{M}}{ }_{(\mathrm{MeOH})}+0.001( \pm 0.067) \mathrm{ASAH}+0.279( \pm 0.115) \mathrm{Mw}$ \\
\hline MR9 & $\mathrm{IC}_{50}(\mathrm{MB} 231)=-108.524( \pm 18.979)+6.283( \pm 5.66) \mathrm{R}_{\mathrm{M}}{ }_{(\mathrm{MeOH})}-0.01( \pm 0.08) \mathrm{ASAH}+0.394( \pm 0.139) \mathrm{Mw}$ \\
\hline
\end{tabular}

Table 6

Results of statistical analysis for MR3-9 models.

\begin{tabular}{|c|c|c|c|c|c|c|c|}
\hline Parameters & MR3 & MR4 & MR5 & MR6 & MR7 & MR8 & MR9 \\
\hline $\mathrm{R}$ & 0.882 & 0.811 & 0.852 & 0.82 & 0.917 & 0.89 & 0.87 \\
\hline $\mathrm{R}^{2}$ & 0.778 & 0.658 & 0.726 & 0.68 & 0.84 & 0.79 & 0.77 \\
\hline $\mathrm{R}^{2}$ adj. & 0.745 & 0.61 & 0.685 & 0.64 & 0.817 & 0.76 & 0.74 \\
\hline F & 23.393 & 12.832 & 17.696 & 14.602 & 35.247 & 25.477 & 22.01 \\
\hline $\mathrm{p}$ & $9.5 \times 10^{-7}$ & $6.7 \times 10^{-5}$ & $7.55 \times 10^{-6}$ & $2.86 \times 10^{-5}$ & $3.55 \times 10^{-8}$ & $4.91 \times 10^{-7}$ & $1.51 \times 10^{-6}$ \\
\hline \multirow[t]{2}{*}{ VIF } & $7.29 \mathrm{R}_{\mathrm{M}}{ }^{0}$ & $1.82 \mathrm{R}_{\mathrm{M}}^{0}$ & $1.82 \mathrm{R}_{\mathrm{M}}^{0}$ & $1.82 \mathrm{R}_{\mathrm{M}}^{0}$ & & & \\
\hline & $2.18 \mathrm{HIA}$ & 7.13ASAH & 7.13ASAH & 7.13ASAH & & & \\
\hline
\end{tabular}

Table 7

Cross validation summary for MR3-9 models.

\begin{tabular}{lllllll}
\hline Factors & MR3 & MR4 & MR5 & MR6 & MR7 & MR8 \\
\hline CV & -0.04 & 0.004 & -0.004 & -0.008 & -0.01 & 0 \\
PRESS & -0.1 & 0.1 & -0.1 & -0.2 & -0.2 & 0.004 \\
SS & $13,233.5$ & 9893.95 & $31,143.197$ & 7033 & $18,320.66$ & $14,741.19$ \\
R $^{2}$ (pred.) & 1 & 0.99 & 0.99 & 0.99 & 0.99 & $19,161.06$ \\
\hline
\end{tabular}

selected which is in accordance with the PCA 3 results that suggest significant influence of these descriptors on retention parameters $\left(\mathrm{R}_{\mathrm{M}}{ }^{0}{ }_{(\mathrm{MeOH})}\right.$ and $\left.\mathrm{R}_{\mathrm{M}}{ }^{0}{ }_{(\mathrm{MeCN})}\right)$. As a result of MR analysis, seven (MR3MR9) statistically significant models were developed (Table 5).

Analyzing established MR3-9 models it can be concluded that all physicochemical parameters $\left(\mathrm{R}_{\mathrm{M}}{ }^{0}{ }_{(\mathrm{MeOH})}, \mathrm{ASAH}\right.$, and Mw) have a positive influence on the\%INH values. Regression coefficients of the $\mathrm{R}_{\mathrm{M}}{ }^{0}{ }_{(\mathrm{MeOH})}$ values indicate that retention parameters have a greater influence on anticancer activity than other physicochemical parameters that form the models. HIA descriptor from MR3 model has a negative influence on the predicted data while PPB manifest positive influence on the anticancer potential of analyzed compounds.

As in the case of previous MR models, the MR(3-9) models were evaluated by comparing the experimental and predicted data (Table S12). According to $\mathrm{R}^{2}$ and $\mathrm{R}^{2}$ adj. values all developed MR models indicate a high correlation between the variables (Table 6). Also, CV error of the anticancer activity prediction is in allowed range (close to zero) (Table 7 ). High values of $\mathrm{R}^{2}$ adj. (in the range from 0.61 to 0.81 ) (Table 6) and PRESS value close to zero (Table 7) for all seven models indicate the good predictive ability of established MR models. High F values (Table 6) verify the good fit of the data. According to VIF values (Table 6), multicollinearity is in the acceptable range $(\mathrm{VIF}<10)$ and VIP values are higher than 0.8 (Table 8).

\subsection{MR models ranking}

In order to rank established MR models, Sum of Ranking differences (SRD) method was applied. This comparing method is nonparametric and robust in common sense. SRD represents an easy tool to evaluate different QSRR models: the smaller is the sum the better is the model. In the ranking of developed MR models, a matrix based on experimentally obtained results (INH\% values of twenty-four compounds determined in 7 different cell lines) was applied as referent rank. The goal was to rank the developed MR models comparing predicted values with experimentally observed $\mathrm{IC}_{50}$ values. The ranking was validated using simulated random numbers for comparison of ranks. The results are best seen with a figure (Fig. 5); the models appearing on the left side of the Gaussian curve are most similar to the referent rank; thus, the performance of MR5 model should be most representative in this ranking procedure. Based on results shown in Fig. 5 Models MR6 and MR7 
Table 8

Variable importance projection values of MR3-9 models.

\begin{tabular}{lllllll}
\hline & MR3 & MR4 & MR5 & MR6 & MR7 & MR8 \\
\hline $\mathrm{R}_{\mathrm{M}}{ }^{\prime}(\mathrm{MeOH})$ & 1.1 & 0.8 & 1 & 1 & & 0.9 \\
$\mathrm{HIA}$ & 0.8 & & & & 1 & \\
$\mathrm{PPB}$ & 1.1 & 1.1 & 1 & 1 & 1 & 1 \\
$\mathrm{ASAH}$ & & 1.1 & 1 & 1 & 1 & 1.8 \\
$\mathrm{Mw}$ & & & & & 1.1 \\
\hline
\end{tabular}

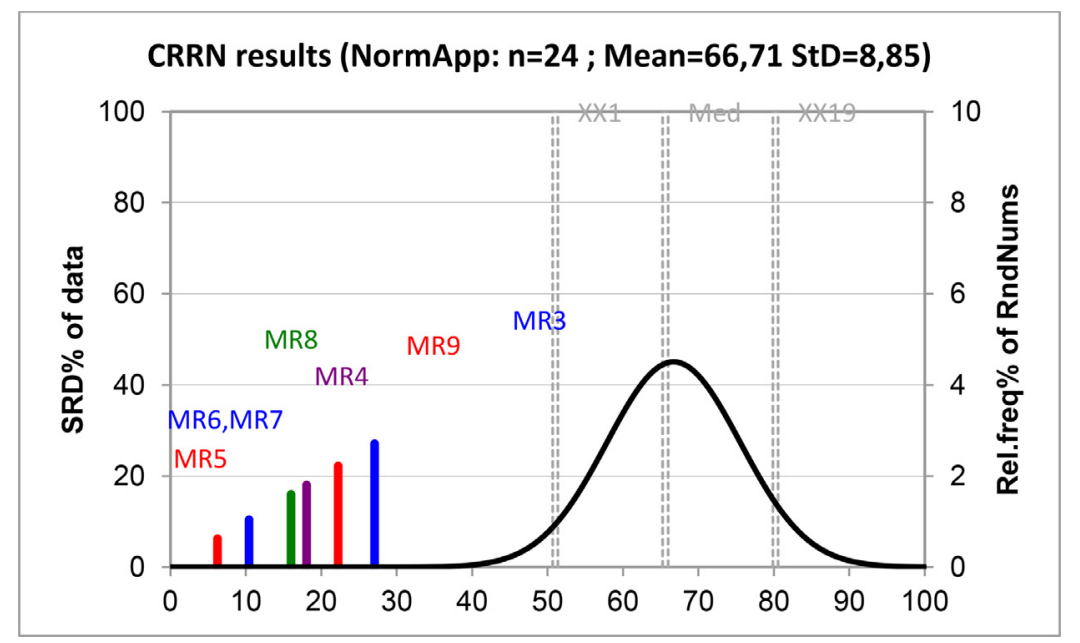

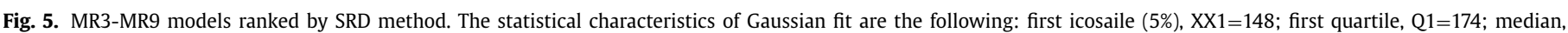
$\mathrm{Med}=190$; last quartile, Q3=208; last icosaile (95\%), XX19=232.

have the same rank and MR3 model is the farthest from the referent rank than all other models. The proximity of obtained SDR values indicates the similarity of the established MR models.

The goal of the conducted correlation analysis was to determine the possibility to predict the anticancer activity of investigated Biginelli hybrids using their retention parameters. It is very important to emphasize that developed models have a very good predictive capability relative to both calibration and external test sets which was confirmed through cross-validation. Obtained MR models could be used in applied conditions in order to avoid expensive and time-consuming molecular biology tests.

\subsection{Antiproliferative activity}

Here we evaluated the in vitro antiproliferative capacity of twenty-four Biginelli hybrids with different substitutions at positions R1, R2, R3, R4, and R5 on a panel of human adherent cancer cell lines. Molecular structures of tested Biginelli hybrids are presented in Table 1 . The compounds were tested against breast (MCF7, MDA-MB-231, and T47D), ovarian (A2780) and cervical (HeLa, SiHa, and C33-A) carcinoma cell lines. Additionally, the tumor selectivity of the most effective compounds was also determined by using non-cancerous mouse embryo fibroblast $(\mathrm{NIH} / 3 \mathrm{~T} 3)$ cells.

In general, among the tested cancer cell lines, SiHa cells were the least susceptible to the examined Biginelli hybrids: only three compounds possessed $\mathrm{IC}_{50}$ values lower than $100 \mu \mathrm{M}$ and most of the compounds exerted weak (lower than 20\%) growth inhibitory effect on cell proliferation (Table 9). However, our positive control 5 -FU inhibited SiHa cell proliferation at a 50\% level in the concentration of $19.2 \mu \mathrm{M}$. On the other hand, our compounds inhibited the most effective proliferation of HeLa cells. More than half of the tested tetrahypyrimidines evoked a considerably stronger antiproliferative effect than 5-FU which was able to evoke a very weak inhibitory effect on HeLa cell proliferation. Based on the antiproliferative effects of Biginelli hybrids against the tested cancer cell lines a susceptibility order of cell lines can be defined: SiHa $<$ MDA-MB$231<$ A2780 < C33A < T47D < MCF-7 < HeLa.

According to the length and type of the $O$-alkyl chain as R2 substituent, a group of compounds can be determined including compounds $8,11,15,16$, and 19 . These analogs differ only in the characteristic of their 0 -alkyl fragment as $\mathrm{R} 2$ substituent of the phenyl ring, therefore, regarding their growth inhibitory data, the impact of these groups on the antiproliferative activity of the tested compounds can be determined. Compound $\mathbf{1 5}$ can be considered as the basic compound of this group. This pyrimidine derivative with a methoxy function at position R2 and hydroxyl group at position R3 did not exert any growth inhibitory effect on the tested gynecological cancer cell lines. Then, compounds $\mathbf{8}$ and $\mathbf{1 1}$ contain groups with three and four carbons at position R2, respectively, and it generated higher cell growth inhibitory potential. Moreover, 11 is one of the most effective Biginelli hybrid with low $\mathrm{IC}_{50}$ values on HeLa $(6.0 \mu \mathrm{M}), \mathrm{MCF}-7(8.3 \mu \mathrm{M})$, and T47D $(7.9 \mu \mathrm{M})$ cell lines (Table 9). The two other derivatives belonging to this group differ in the characteristic of their substituents at position $\mathrm{R} 2$ of phenyl ring. Compound 16 bears $\mathrm{OCH}_{2} \mathrm{COOCH}_{2} \mathrm{CH}_{3}$ group which cannot consider being beneficial regarding antiproliferative activity because it exerted cell growth inhibitory effect with maximum 30\%. Molecule 19 contains a bulky 0 -benzyl group which increased its antiproliferative activity on all investigated cancer cell lines except for $\mathrm{SiHa}$ cells compared to $\mathbf{1 5}$, the basic derivative of this group. The calculated $\mathrm{IC}_{50}$ value on HeLa cells of this Biginelli hybrid is $7.7 \mu \mathrm{M}$, therefore it is the other most effective compound among the tested derivatives (Table 9).

Therefore, two methoxy groups can be found as R2 and R3 substituents in compounds 14 and 22, whereas compound 23 possesses three methoxy groups as R2, R3, and R4 substituents. Based on their antiproliferative data it can be concluded that two or three methoxy groups on phenyl ring are not beneficial, because it eliminated the cell growth inhibitory activity of the compounds compared to that of $\mathbf{1 9}$ which contains one methoxy and one $O$ - 
Table 9

Antiproliferative properties of Biginelli hybrids.

\begin{tabular}{|c|c|c|c|c|c|c|c|c|}
\hline \multirow[b]{2}{*}{ Comp. } & \multirow[b]{2}{*}{ Conc. $(\mu \mathrm{M})$} & \multicolumn{2}{|c|}{$\begin{array}{l}\text { Growth inhibition; } \% \pm \mathrm{SEM} \\
\left.\text { [calculated } \mathrm{IC}_{50} \text { value; } \mu \mathrm{M}\right]^{¥}\end{array}$} & \multirow[b]{2}{*}{ C33A } & \multirow[b]{2}{*}{ A2780 } & \multirow[b]{2}{*}{ MCF-7 } & \multirow[b]{2}{*}{ T47D } & \multirow[b]{2}{*}{ MDA-MB-231 } \\
\hline & & HeLa & $\mathrm{SiHa}$ & & & & & \\
\hline \multirow[t]{2}{*}{1} & 30 & $-*$ & - & - & - & $20.95 \pm 1.19$ & - & - \\
\hline & $100 \|$ & $\begin{array}{l}50.59 \pm 0.28 \\
{[\mathbf{9 9 . 1}]^{\#}}\end{array}$ & - & - & - & $33.40 \pm 0.14$ & $35.14 \pm 3.63$ & - \\
\hline \multirow[t]{2}{*}{2} & 30 & $47.37 \pm 0.86$ & - & $36.08 \pm 1.40$ & $30.71 \pm 1.99$ & $39.74 \pm 1.28$ & $26.07 \pm 1.33$ & $36.61 \pm 3.58$ \\
\hline & 100 & $\begin{array}{l}70.52 \pm 1.09 \\
{[\mathbf{2 8 . 8}]}\end{array}$ & $26.20 \pm 0.76$ & $\begin{array}{l}55.64 \pm 0.99 \\
{[69.3]}\end{array}$ & $\begin{array}{l}87.82 \pm 1.61 \\
{[49.9]}\end{array}$ & $\begin{array}{l}68.68 \pm 2.81 \\
{[35.8]}\end{array}$ & $\begin{array}{l}64.22 \pm 1.39 \\
{[\mathbf{6 4 . 6}]}\end{array}$ & $44.35 \pm 2.34$ \\
\hline \multirow[t]{2}{*}{3} & 30 & $51.07 \pm 1.75$ & - & $38.83 \pm 4.02$ & $31.08 \pm 3.68$ & $35.88 \pm 0.67$ & $25.96 \pm 2.48$ & $31.37 \pm 3.70$ \\
\hline & 100 & $\begin{array}{l}70.49 \pm 0.88 \\
{[29.3]}\end{array}$ & - & $\begin{array}{l}54.57 \pm 1.64 \\
{[74.5]}\end{array}$ & $\begin{array}{l}52.79 \pm 1.69 \\
{[89.9]}\end{array}$ & $\begin{array}{l}63.98 \pm 2.21 \\
{[49.1]}\end{array}$ & $\begin{array}{l}50.27 \pm 0.98 \\
{[\mathbf{9 8 . 9 ]}}\end{array}$ & $45.33 \pm 3.10$ \\
\hline \multirow[t]{2}{*}{4} & 30 & $47.69 \pm 1.59$ & - & $37.22 \pm 1.80$ & $56.4 \pm 4.79$ & $42.25 \pm 2.60$ & $27.45 \pm 0.77$ & $38.34 \pm 3.93$ \\
\hline & 100 & $\begin{array}{l}63.12 \pm 1.04 \\
{[\mathbf{2 5 . 8}]}\end{array}$ & $45.89 \pm 2.29$ & $\begin{array}{l}67.32 \pm 0.47 \\
{[48.5]}\end{array}$ & $\begin{array}{l}90.84 \pm 3.54 \\
{[\mathbf{2 2 . 1}]}\end{array}$ & $\begin{array}{l}95.78 \pm 1.68 \\
{[\mathbf{3 1 . 3}]}\end{array}$ & $\begin{array}{l}83.86 \pm 1.48 \\
{[44.3]}\end{array}$ & $\begin{array}{l}90.75 \pm 1.80 \\
{[\mathbf{3 4 . 4 ]}}\end{array}$ \\
\hline \multirow[t]{2}{*}{5} & 30 & $47.13 \pm 2.30$ & - & $38.15 \pm 1.42$ & $37.91 \pm 0.69$ & $47.84 \pm 1.29$ & $33.08 \pm 1.58$ & $32.24 \pm 2.91$ \\
\hline & 100 & $\begin{array}{l}92.74 \pm 1.22 \\
{[\mathbf{2 9 . 4}]}\end{array}$ & $\begin{array}{l}82.31 \pm 2.64 \\
{[89.7]}\end{array}$ & $\begin{array}{l}94.04 \pm 0.71 \\
{[35.9]}\end{array}$ & $\begin{array}{l}97.35 \pm 0.26 \\
{[\mathbf{3 5 . 2}]}\end{array}$ & $\begin{array}{l}99.42 \pm 0.13 \\
{[\mathbf{2 5 . 6}]}\end{array}$ & $\begin{array}{l}99.00 \pm 0.23 \\
{[37.2]}\end{array}$ & $\begin{array}{l}92.33 \pm 1.15 \\
{[\mathbf{3 5 . 6}]}\end{array}$ \\
\hline \multirow[t]{2}{*}{6} & 30 & $22.82 \pm 2.60$ & - & - & - & - & - & - \\
\hline & 100 & - & - & - & - & - & - & - \\
\hline \multirow[t]{2}{*}{7} & 30 & $33.08 \pm 2.58$ & - & $24.48 \pm 2.86$ & - & $24.49 \pm 2.17$ & $22.00 \pm 1.45$ & $30.29 \pm 1.28$ \\
\hline & 100 & $\begin{array}{l}64.78 \pm 0.06 \\
{[49.8]}\end{array}$ & $22.25 \pm 0.91$ & $39.41 \pm 1.68$ & $30.85 \pm 2.23$ & $44.1 \pm 2.15$ & $33.46 \pm 0.61$ & $27.96 \pm 5.50$ \\
\hline \multirow[t]{2}{*}{8} & 30 & $39.71 \pm 0.72$ & - & $36.21 \pm 1.69$ & $36.53 \pm 2.66$ & $36.66 \pm 0.99$ & - & $25.35 \pm 0.44$ \\
\hline & 100 & $\begin{array}{l}67.30 \pm 0.38 \\
{[\mathbf{4 1 . 8}]}\end{array}$ & $25.24 \pm 1.51$ & $48.95 \pm 2.04$ & $\begin{array}{l}57.40 \pm 1.03 \\
{[64.9]}\end{array}$ & $\begin{array}{l}57.37 \pm 1.91 \\
{[\mathbf{5 7 . 4}]}\end{array}$ & $43.68 \pm 1.80$ & $40.42 \pm 0.34$ \\
\hline \multirow[t]{2}{*}{9} & 30 & $34.19 \pm 0.73$ & - & $27.85 \pm 2.69$ & - & - & $29.49 \pm 2.28$ & - \\
\hline & 100 & $\begin{array}{l}69.06 \pm 0.72 \\
{[\mathbf{5 0 . 8}]}\end{array}$ & $31.69 \pm 2.74$ & $\begin{array}{l}57.93 \pm 3.04 \\
{[\mathbf{6 1 . 1}]}\end{array}$ & $\begin{array}{l}59.59 \pm 1.47 \\
{[\mathbf{8 1 . 1}]}\end{array}$ & $\begin{array}{l}55.56 \pm 1.04 \\
{[\mathbf{8 9 . 5}]}\end{array}$ & $47.62 \pm 1.04$ & $49.21 \pm 2.50$ \\
\hline \multirow[t]{2}{*}{10} & 30 & $48.19 \pm 0.62$ & $26.57 \pm 1.78$ & $25.93 \pm 1.66$ & $42.27 \pm 0.66$ & $27.44 \pm 2.26$ & $25.86 \pm 1.90$ & $28.19 \pm 2.98$ \\
\hline & 100 & $\begin{array}{l}72.62 \pm 0.14 \\
{[27.9]}\end{array}$ & $27.94 \pm 0.95$ & $50.09 \pm 2.65$ & $\begin{array}{l}54.50 \pm 0.13 \\
{[63.8]}\end{array}$ & $\begin{array}{l}50.98 \pm 1.45 \\
{[\mathbf{9 8 . 4}]}\end{array}$ & $\begin{array}{l}53.07 \pm 2.30 \\
{[\mathbf{9 3 . 8}]}\end{array}$ & $42.27 \pm 1.93$ \\
\hline \multirow[t]{2}{*}{11} & 30 & $74.48 \pm 1.01$ & $55.97 \pm 2.09$ & $61.19 \pm 0.39$ & $43.03 \pm 1.31$ & $76.71 \pm 0.16$ & $68.96 \pm 0.41$ & $46.00 \pm 3.22$ \\
\hline & 100 & $\begin{array}{l}83.80 \pm 0.33 \\
{[\mathbf{6 . 0}]}\end{array}$ & $\begin{array}{l}55.24 \pm 0.87 \\
{[\mathbf{2 5 . 9 ]}}\end{array}$ & $\begin{array}{l}78.37 \pm 0.20 \\
{[\mathbf{1 6 . 9 ]}}\end{array}$ & $\begin{array}{l}75.87 \pm 1.40 \\
{[\mathbf{3 6 . 4}]}\end{array}$ & $\begin{array}{l}83.69 \pm 0.69 \\
{[8.3]}\end{array}$ & $\begin{array}{l}70.42 \pm 0.94 \\
{[7.9]}\end{array}$ & $\begin{array}{l}53.89 \pm 1.47 \\
{[47.1]}\end{array}$ \\
\hline \multirow[t]{2}{*}{12} & 30 & $59.48 \pm 0.53$ & - & $53.17 \pm 4.07$ & $20.79 \pm 2.39$ & - & $21.80 \pm 0.85$ & $26.70 \pm 0.45$ \\
\hline & 100 & $\begin{array}{l}68.75 \pm 1.06 \\
{[\mathbf{5 1 . 3}]}\end{array}$ & $\begin{array}{l}57.66 \pm 1.49 \\
{[86.3]}\end{array}$ & $\begin{array}{l}98.52 \pm 0.55 \\
{[21.7]}\end{array}$ & $\begin{array}{l}97.48 \pm 0.26 \\
{[\mathbf{4 2 . 5}]}\end{array}$ & $\begin{array}{l}68.78 \pm 1.88 \\
{[63.4]}\end{array}$ & $\begin{array}{l}79.58 \pm 2.00 \\
{[43.1]}\end{array}$ & $\begin{array}{l}76.51 \pm 1.03 \\
{[\mathbf{4 6 . 8}]}\end{array}$ \\
\hline \multirow[t]{2}{*}{13} & 30 & - & - & - & - & - & - & $30.37 \pm 2.68$ \\
\hline & 100 & $46.58 \pm 0.94$ & $34.35 \pm 1.99$ & $26.24 \pm 0.04$ & - & $34.48 \pm 4.04$ & $27.82 \pm 1.60$ & $29.02 \pm 0.54$ \\
\hline 14 & 30 & & - & - & - & - & - & - \\
\hline & 100 & $33.23 \pm 0.97$ & - & $22.11 \pm 2.66$ & - & $24.31 \pm 2.31$ & - & - \\
\hline 15 & 30 & - & - & - & - & - & - & $28.00 \pm 1.03$ \\
\hline & 100 & $32.37 \pm 1.21$ & - & - & - & - & $26.06 \pm 1.51$ & $20.32 \pm 2.53$ \\
\hline 16 & 30 & - & $27.66 \pm 0.65$ & - & - & - & - & - \\
\hline & 100 & $28.95 \pm 1.00$ & $36.30 \pm 1.49$ & - & - & $30.90 \pm 0.52$ & $28.86 \pm 0.02$ & $29.77 \pm 3.55$ \\
\hline 17 & 30 & - & - & - & - & - & - & - \\
\hline & 100 & - & - & - & - & - & - & - \\
\hline 18 & 30 & - & - & - & - & - & - & - \\
\hline & 100 & $48.01 \pm 4.32$ & - & - & - & - & - & - \\
\hline 19 & 30 & $69.04 \pm 1.32$ & - & $47.80 \pm 1.91$ & $45.26 \pm 0.86$ & $56.67 \pm 2.59$ & $50.17 \pm 0.96$ & $31.43 \pm 2.26$ \\
\hline & 100 & $\begin{array}{l}81.39 \pm 1.77 \\
{[7.7]}\end{array}$ & $43.5 \pm 1.39$ & $\begin{array}{l}74.88 \pm 2.14 \\
{[\mathbf{2 4 . 5}]}\end{array}$ & $\begin{array}{l}63.47 \pm 0.37 \\
{[47.5]}\end{array}$ & $\begin{array}{l}69.90 \pm 2.73 \\
{[27.0]}\end{array}$ & $\begin{array}{l}72.99 \pm 0.07 \\
{[33.5]}\end{array}$ & $\begin{array}{l}50.00 \pm 1.96 \\
{[\mathbf{9 2 . 5}]}\end{array}$ \\
\hline 20 & 30 & $23.36 \pm 1.74$ & - & - & - & - & - & - \\
\hline & 100 & $\begin{array}{l}51.91 \pm 0.12 \\
{[79.8]}\end{array}$ & - & - & - & - & - & - \\
\hline 21 & 30 & - & - & - & - & $26.36 \pm 0.22$ & $24.60 \pm 1.66$ & - \\
\hline & 100 & $20.84 \pm 0.12$ & - & - & - & $39.88 \pm 3.01$ & $33.86 \pm 0.65$ & - \\
\hline 22 & 30 & - & - & - & - & $34.13 \pm 3.27$ & - & - \\
\hline & 100 & $37.98 \pm 0.47$ & - & - & - & $34.94 \pm 0.75$ & - & - \\
\hline 23 & 30 & - & - & - & - & - & $20.72 \pm 0.67$ & - \\
\hline & 100 & - & $23.09 \pm 1.22$ & - & - & - & $33.90 \pm 0.62$ & - \\
\hline
\end{tabular}


Table 9 (continued)

\begin{tabular}{|c|c|c|c|c|c|c|c|c|}
\hline \multirow[t]{2}{*}{ Comp. } & \multirow[t]{2}{*}{ Conc. $(\mu \mathrm{M})$} & \multicolumn{7}{|c|}{$\begin{array}{l}\text { Growth inhibition; } \% \pm \mathrm{SEM} \\
\left.\text { [calculated } \mathrm{IC}_{50} \text { value; } \mu \mathrm{M}\right]^{*}\end{array}$} \\
\hline & & HeLa & $\mathrm{SiHa}$ & C33A & A2780 & MCF-7 & T47D & MDA-MB-231 \\
\hline \multirow[t]{2}{*}{24} & 30 & $24.46 \pm 5.28$ & - & - & - & - & - & - \\
\hline & 100 & $\begin{array}{l}72.98 \pm 2.97 \\
{[\mathbf{5 7 . 3}]}\end{array}$ & - & $35.50 \pm 0.30$ & $28.94 \pm 1.45$ & $28.30 \pm 1.11$ & $32.36 \pm 2.44$ & - \\
\hline \multirow[t]{2}{*}{ 5-FU } & 10 & $22.69 \pm 0.89$ & $40.98 \pm 0.98$ & $35.18 \pm 1.36$ & $62.22 \pm 2.35$ & $30.47 \pm 1.38$ & $43.37 \pm 0.91$ & $45.82 \pm 3.09$ \\
\hline & 30 & $\begin{array}{l}25.60 \pm 0.79 \\
\text { [n.e.] } \S\end{array}$ & $\begin{array}{l}57.07 \pm 1.18 \\
{[\mathbf{1 9 . 2}]}\end{array}$ & $\begin{array}{l}49.97 \pm 1.25 \\
{[\mathbf{2 4 . 8}]}\end{array}$ & $\begin{array}{l}69.06 \pm 1.83 \\
{[8.5]}\end{array}$ & $\begin{array}{l}43.84 \pm 0.85 \\
{[\mathbf{4 2 . 9 ]}}\end{array}$ & $\begin{array}{l}52.54 \pm 0.72 \\
{[\mathbf{2 2 . 9}]}\end{array}$ & $\begin{array}{l}59.72 \pm 1.36 \\
{[\mathbf{1 3 . 7 ]}}\end{array}$ \\
\hline
\end{tabular}

$¥$ Mean value from two independent measurements with five parallel wells; standard deviation $<20 \%$.

* Growth inhibition values $<20 \%$ are not presented.

\# $\mathrm{IC}_{50}$ values have been calculated if the growth inhibition value of the compound at $100 \mu \mathrm{M}$ concentration is higher than $50 \%$.

$\S$ n.e. $=$ not effective, the calculated $\mathrm{IC}_{50}$ value of 5-FU is higher than $100 \mu \mathrm{M}$.

\| \%INH values.

benzyl group as R2 and R3 substituents (Table 9). If the $3^{\prime}, 4^{\prime}-$ dimethoxyphenyl fragment changed with $p$-chlorophenyl modest antiproliferative activity selective to HeLa cell line was obtained (compound 24).

Another group of Biginelli derivatives can be created from compounds 4, 5, and 21 because these analogs differ from each other in the length of the halogenated alkyl chain at position R2 of the phenyl ring only. 21 contains a hydroxyl group as R2 substituent, therefore it is the basic derivative of this group. The mentioned compound did not exert a substantial cell growth inhibitory effect against the tested cancer cell lines, because it was able to inhibit cell proliferation at a maximum of $40 \%$ (Table 9). After furnishing halogenated alkyl chains (i.e. bromobutoxy or bromopentoxy) the antiproliferative activity substantially increased on all tested cancer cell lines compared to 21. However, there is no sifnificant difference between the $\mathrm{IC}_{50}$ values of $\mathbf{4}$ and $\mathbf{5}$ except on SiHa cells, therefore the length of the chain has no impact on the pharmacological effect in this case. One more Br-containing Biginelli derivative has been tested, compound 12, which possesses methyl ester fragment at position R1, unlike the other members of this group. Its antiproliferative capacity can be compared to that of 8 because their chemical structure differs in one Br-atom only. The incorporation of the halogen atom increased the cell growth inhibitory potential of 12, except on HeLa cells, however, this modification led to a medium-effective THPM (Table 9).

The influence of the structure of the function group at position R1 can also be the basis of a comparison among the tested THPM analogs. Compounds $\mathbf{3}$ and $\mathbf{1 0}$ possess a similar chemical structure with a long, branched-chain substituent with double $\mathrm{C}-\mathrm{C}$ bound as R2 function group, however, they are methyl ester and ethyl ester derivatives, respectively, regarding position R1. The longer function group at position R1 slightly increased the antiproliferative activity of 3. A very similar trend can be observed in the case of cell growth inhibitory potential of compounds $\mathbf{2}$ and $\mathbf{9}$, which contain O-butenyl group at position R2 (Table 9). Compound $\mathbf{1 3}$ has $O$-allyl function. This slight structural modification resulted in the decreased antiproliferative activity of $\mathbf{1 3}$ compared to $\mathbf{9}$. Moreover, compounds $\mathbf{8}$ and $\mathbf{1 3}$ contain the corresponding 0 -propyl and $O$-propenyl (allyl) function, respectively. The presence of unsaturated bond reduced antiproliferative activity of $\mathbf{1 3}$ compared to $\mathbf{8}$ (Table 9).

The following three Biginelli hybrids possess acetyl group as R1 substituent $(\mathbf{6}, \mathbf{1 7}$, and $\mathbf{2 0})$, however, they have various substituents on THPMs core. Presumably, due to the presence of acetyl group these molecules did not exert any substantial antiproliferative activity against the tested cancer cell lines except of $\mathbf{2 0}$ which inhibited HeLa cell proliferation with $\mathrm{IC}_{50}$ value of $79.8 \mu \mathrm{M}$ (Table 9).

Two 2-thioxo analogs, compounds $\mathbf{1}$ and $\mathbf{7}$ have been tested against gynecological cancer cell lines. Although they differ from each other in the substitution pattern of phenyl ring, it does not have a significant impact on their antiproliferative capacities: both compounds were able to inhibit HeLa cell proliferation with modest $\mathrm{IC}_{50}$ values ( $99.1 \mu \mathrm{M}$ and $49.8 \mu \mathrm{M}$, respectively) but they could not substantially influence cell growth of other examined cancer cell lines (Table 9).

In summary, two compounds (11 and 19) among of twenty-four investigated THPMs have been identified as promising cell proliferation inhibiting agents on HeLa cell line. Additionally, compound 11 was able to suppress proliferation of MCF-7 and T47D cell lines with low $\mathrm{IC}_{50}$ values. Their antiproliferative activities against these cancer cell lines exceed that of our positive control, 5-FU with at least one order of magnitude. Moreover, tumor-selectivity of these two effective compounds has also been examined by means of MTT-assay against mouse embryo fibroblast cells. The $\mathrm{IC}_{50}$ values of 11 and 19 on fibroblast cells are 92.3 and $31.1 \mu \mathrm{M}$, respectively. High selectivity index of $\mathbf{1 1}$ and $\mathbf{1 9}$ (15.4 and 4.0, respectively) indicate that their cell proliferation inhibitory activities can be considered as selective to the tumor cells (Table 10).

\section{Material and methods}

Biginelli hybrids were synthesized using earlier described methods [13,14]. Methanol and acetonitrile (HPLC grade) were purchased by Sigma.

\subsection{Chromatographic behavior of selected Biginelli hybrids}

In this work, twenty-four Biginelli hybrids were exploited for the establishment of their molecular properties. For the evaluation of retention parameters RP TLC analysis was employed. In this analysis solutions of analytes were prepared in concentration of $1 \mathrm{mg} / \mathrm{mL}$. Analytes were applied on the RP TLC plate as individual bands, and the plates were developed using $\mathrm{MeOH} / \mathrm{H}_{2} \mathrm{O}$ and $\mathrm{MeCN} / \mathrm{H}_{2} \mathrm{O}$ solvent systems with $\Phi(\mathrm{MeCN} / \mathrm{MeOH})=0.5-0.7 \mathrm{v} / \mathrm{v}$. In experiments, $1 \mu \mathrm{L}$ aliquot of each analyte solution was spotted on the plate using a micropipette. Plates are then developed in a chamber tank (Camag) which was saturated with the appropriate eluent overnight at $25^{\circ} \mathrm{C}$. The experiment was performed on RP-18 modified silica gel F $254 \mathrm{~s}(20 \times 20 \mathrm{~cm})$ plates (Merck Darmstadt). The spots of analytes are visualized using UV lamp at $254 \mathrm{~nm}$. Each RP-TLC analysis was performed in triplicate under equal conditions of temperature and humidity. No significant statistical differences of the retention factor $\left(R_{f}\right)$ were observed. The retention constants $\left(R_{M}\right)$ were calculated using the equation:

$\mathrm{R}_{\mathrm{M}}=\log \left(1 / \mathrm{R}_{\mathrm{f}}-1\right)$

$R_{f}$ represents retention factor and $R_{M}$ values linearly depend on the logarithm of concentration organic modifier in the mobile phase according to Soczewinski [19]

$\mathrm{R}_{\mathrm{M}}=\mathrm{R}_{\mathrm{M}}^{0}+\mathrm{b} \log \mathrm{C}$ 
Table 10

Selectivity index [SI $=\mathrm{IC}_{50}(\mathrm{NIH} / 3 \mathrm{~T} 3) / \mathrm{IC}_{50}$ (cancer cell line)] of $\mathbf{1 1}$ and $\mathbf{1 9}$.

\begin{tabular}{|c|c|c|c|c|c|c|c|c|c|}
\hline & & HeLa & $\mathrm{SiHa}$ & $\mathrm{C} 33 \mathrm{~A}$ & A2780 & MCF-7 & T47D & MDA-MB-231 & $\mathrm{NIH} / 3 \mathrm{~T} 3$ \\
\hline \multirow[t]{2}{*}{11} & $\mathrm{IC}_{50}$ & 6.0 & 25.9 & 16.9 & 36.4 & 8.3 & 7.9 & 47.1 & 92.3 \\
\hline & SI & 15.4 & 3.5 & 5.5 & 2.5 & 11.1 & 11.7 & 1.9 & - \\
\hline \multirow[t]{2}{*}{19} & $\mathrm{IC}_{50}$ & 7.7 & - & 24.5 & 47.5 & 27.0 & 33.5 & 92.5 & 31.1 \\
\hline & SI & 4.0 & - & 1.3 & - & 1.1 & - & - & - \\
\hline
\end{tabular}

$\mathrm{R}_{\mathrm{M}}{ }^{0}$ represents intercept, b slope (Table $\mathrm{S} 1$ ) of the linear plot and $\mathrm{C}$ is the concentration of the organic solvent (50-70 in\%) in the mobile phase.

\subsection{Cell lines}

The cell division inhibiting capacities of the newly synthesized compounds (1-24) were determined on a panel of human adherent cancer cell lines. MCF-7, MDA-MB-231, and T47D were isolated from breast cancers differing in the biochemical background, while A2780 cells were isolated from ovarian cancer. HeLa and SiHa are cervical cancer cell lines positive for HPV-18 and HPV-16, respectively, while C33A cervical cancer cells are negative for HPV. The cancer selectivity of compounds was tested on the non-cancerous mouse embryo fibroblast cell line $\mathrm{NIH} / 3 \mathrm{~T} 3$. All cell lines were purchased from the European Collection of Cell Cultures (ECCAC, Salisbury, UK) exception for SiHa and C33A (American Tissue Culture Collection, Manassas, VA, USA). All cells were maintained in minimal essential medium (MEM) supplemented with $10 \%$ fetal bovine serum (FBS), 1\% nonessential amino acids (NEAA), and 1\% antibiotic-antimycotic mixture (AAM). All media and supplements were obtained from Lonza Group Ltd., Basel, Switzerland. All chemicals were purchased from Sigma-Aldrich Ltd. (Budapest, Hungary).

\subsection{MTT assay}

The antiproliferative effects of the test compounds were measured by the means of the MTT assay on all of the cell lines mentioned above. $50 \mathrm{mM}$ stock solutions of all compounds were prepared using dimethyl sulfoxide (DMSO). The highest applied DMSO concentration of the medium $(0.2 \%)$ did not exert any substantial effect on the investigated cellular functions. Cells were grown in a humidified atmosphere containing $5 \% \mathrm{CO}_{2}$ at $37{ }^{\circ} \mathrm{C}$. For our investigations, cells were seeded into 96 -well plates at the density of 5000 cells/well, except of C33A, which was seeded at the density of 10000 cells/well. Cells were allowed to stand overnight under the same conditions as mentioned before. $24 \mathrm{~h}$ later, cells were treated with medium containing the test compounds in 3 different concentrations $(10,30$, and $100 \mu \mathrm{M})$ and left for incubation for another $72 \mathrm{~h}$. After incubation, cell viability was determined by adding $20 \mu \mathrm{l}$ MTT solution $(5 \mathrm{mg} / \mathrm{ml}$ ) for $4 \mathrm{~h}$. The precipitated formazan crystals were solubilized in $100 \mu \mathrm{L}$ DMSO during a 60 -min period of shaking at $37{ }^{\circ} \mathrm{C}$. The reduced MTT was assayed at $545 \mathrm{~nm}$, using a microplate reader (SPECTROstar Nano, BMG Labtech $\mathrm{GmbH}$, Offenburg, Germany) utilizing wells with untreated cells serving as control. [20] An independent experiment was performed on all cell lines using 5-fluorouracil (5-FU) as positive control in the same concentrations as the test compounds. For the most effective compounds, exceeding $50 \%$ of growth inhibition in $10 \mu \mathrm{M}$, tests were repeated utilizing a broader range of concentrations $(0.1-30 \mu \mathrm{M})$, furthermore, compounds 11 and 19 were also tested on NIH-3T3 (mouse fibroblast) cells to determine cancer selectivity. Sigmoidal dose-response curves were fitted on the acquired data to determine the $\mathrm{IC}_{50}$ values of the compounds using GraphPad Prism 5.01 (GraphPad Software, Inc., San Diego, CA, USA).

\subsection{Molecular descriptors calculation and establishment of QSRR models}

Molecular properties were calculated based on 2D and 3D molecular structures. 3D structures of examined molecules were optimized by applying the molecular mechanics force field method. To compare experimental results with calculated values for tested THPMs different software were applied such as: Molinspiration (https://www.molinspiration.com/), SwissADME (http://www. swissadme.ch/) MarvinSketch 21.1, PreADMET (https://preadmet. bmdrc.kr/), and Chem 3D Ultra 8.0 (http://www.cambridgesoft. com). Namely, twenty-seven descriptors were calculated and presented in Tables S2-S4: ChemDraw Ultra 8.0 provided three $\log \mathrm{P}$ values (LogP, CLogP, and LogS-Crippen's method) calculated on the basis of fragmental and atom based methods; Molinspiration was used for calculation of miLogP values, Mw, V and Lipinski "rule of five" applying fragmental based methods; other logP values were calculated by the software SwissADME (iLOGP-physics based method, MLOGP-Moriguchi's method, XLOGP3-Atomistic method, WLOGP-Atomistic method, SILICOS-IT-Hybrid fragmental/topological method, Consensus LogPo/w-Average of all five predictions). MarvinSketch was applied in order to calculate $\log D$ at $\mathrm{pH}$ of 7.4, POL-Polarizability, HLB-Hydrophilic-Lipophilic Balance, vdWSA-van der Waals Surface Area, ASA-solvent accessible surface area calculated using the radius of the solvent $\left(1.4^{\circ} \mathrm{A}\right.$ for the water molecule), ASA+-solvent accessible surface area of all atoms with positive partial charge (explicitly greater than 0), ASA- -solvent accessible surface area of all atoms with negative partial charge (explicitly less than 0), ASA-H-solvent accessible surface area of all hydrophobic atoms $(|q i|<0.125$; |qi| is the absolute value of the partial charge of the atom).

For the calculation of different pharmacokinetic parameters Molinspiration and PreADMET software were used: PPB[\%]-Plasma Protein Binding, BBB-Blood-Brain Barrier penetration, Caco2penetration in heterogeneous human epithelial colorectal adenocarcinoma cells, HIA-Human Intestinal Absorption, MDCK-MadinDarby Canine Kidney cells permeability, and GPCR-G-proteincoupled receptor ligand. Molecular descriptors that are included in this study are chosen by appropriate descriptor selection procedures for further QSRR modeling.

\subsection{Chemometric analysis}

In this work for purpose of chemometrics analysis, we applied unsupervised (principal component analysis - PCA and hierarchical cluster analysis - HCA) and supervised (sum of ranking differencesSRD and multiple linear regression-MR) pattern recognition methods. HCA, PCA, and MR analysis were performed using OriginPro 2016 software package. SRD method was carried out according to the script published by K. Héberger and K. Kollár-Hunek. [12,21] For HCA as the default distance measure was applied the Euclidean distance. It represents the square root of the sum of the square differences. PCA analysis is based on correlation matrix. In this study calculated ADME and physicochemical descriptors, together with retention values and in\% expressed inhibition of cell proliferation at $100 \mu \mathrm{M}$ of Biginelli hybrids (\%INH, Table S5) were subjected to PCA analysis. Obtained results were meant to enable the specific 
clusterization of the investigated Biginelli hybrids because of their similar physicochemical and ADME characteristics with experimental data.

Multiple linear regression is the method that includes more than one independent variable in correlation with the dependent variable. [22] Even though regression analysis can be performed by numerous different techniques, least squares represent one of the most applied techniques in this process. To properly establish MR models certain criteria should be fulfilled: (1) absence of multicollinearity between variables and (2) the ratio of the number of data and number of variables should be higher than 5. [23] Multicollinearity can be expressed within the variance inflation factor (VIF) which should not be higher than 10 .

In this work, SRD analysis was performed using experimentally obtained anticancer activities (\%INH, Table S5) and their predicted values (Table S12) for all tested compounds. This analysis was performed to evaluate established MR models in the context of their prediction of anticancer properties of examined compounds. For this purpose, the data are arranged in a matrix form. Objects (predicted\%INH) are placed in columns, and examined molecules are listed in the rows. The average row values of the experimentally obtained data were selected as the reference ranking.

\section{Conclusion}

According to the presented results, the MR1 and MR2 models can be recommended for precise prediction of the retention parameters of structurally similar Bigineli hybrids using RP-TLC chromatography. Obtained results of this QSRR study confirm the influence of molecular lipophilicity on the retention behavior under the specified chromatographic conditions. MTT assay confirmed that compounds 11 and 19 presents the most promising candidates with excellent selectivity toward cancer cells and with satisfactory pharmacokinetic properties. The best biological activity was observed among molecules that belong to group II (methyl ester). The anticancer activity of these compounds was associated with the presence of hydrophobic substituents in the molecule such as phenyl and alkyl groups. Established MR3-9 models have proven to be very useful tools in the prediction of anticancer activity of THPMs. Their quality was confirmed through internal and external statistical validation. Finally, the first pharmacokinetic profile for the validation of THPMs activity was presented. Through comparison of experimental and predicted and experimental and residual data, it was confirmed that developed MR models can be valuable in the design of novel Biginelli molecules. Their very good predictive performance was confirmed also by SRD analysis.

\section{Declaration of Competing Interest}

The authors declare that there is no conflict of interest.

\section{Acknowledgement}

The results are the part of the projects: Agreements No. 45103-9/2021-14/200378 and 451-03-1766/2020-14/1, supported by the Ministry of Education, Science, and Technological Development of the Republic of Serbia. Support from Ministry of Human Capacities, Hungary grant 20391-3/2018/FEKUSTRAT is acknowledged. The authors thank the support of project EFOP-3.6.2-162017-00005.

\section{Supplementary materials}

Supplementary material associated with this article can be found, in the online version, at doi:10.1016/j.molstruc.2022.132373.

\section{References}

[1] R. Kaur, P. Kaur, S. Sharma, G. Singha, S. Mehndiratta, P.M.S. Bedia, K. Nepalia, Anti-cancer pyrimidines in diverse scaffolds: a review of patent literature, Recent Patents Anti-Cancer Drug, Discov 10 (2015) 23-71.

[2] P. Biginelli, Aldureides of ethylic acetoacetate and ethylic oxaloacetate, Gazz. Chim. Ital. 23i (1893) 360-416.

[3] L.V. Chopda, P.N. Dave, Recent advances in homogeneous and heterogeneous catalyst in Biginelli reaction from 2015 to 19: a concise review, ChemistrySelect 5 (2020) 5552-5572.

[4] S.S. Panda, P. Khanna, L. Khanna, Biginelli reaction: a green perspective, Curr. Org. Chem. 16 (2012) 507-520.

[5] S. Mahgoub, M.-.K. El-Sayed, M.F. El-Shehry, S.M. Awad, Y.E. Mansour, S.S. Fatahala, Synthesis of novel calcium channel blockers with ACE2 inhibition and dual antihypertensive /anti-inflammatory effects: a possible therapeutic tool for COVID-19, Bioorg. Chem. (2021) 105272

[6] R. Kaur, S. Chaudhary, K. Kumar, M.K. Gupta, R.K. Rawa, Recent synthetic and medicinal perspectives of dihydropyrimidinones: a review, Eur. J. Med. Chem. 132 (2017) 108-134.

[7] T.U. Mayer, T.M. Kapoor, S.J. Haggarty, R.W. King, S.L. Schreiber, T.J. Mitchison, Small molecule inhibitor of mitotic spindle bipolarity identified in a phenotype-based screen, Science 286 (1999) 971-974.

[8] J.B. Taylor, D.J. Triggle (Eds.), Comprehensive Medicinal Chemistry II Elsevier Ltd., 2007 Editors-in-ChiefVolume 5 and 6.

[9] S. Kovačević, M. Karadžić Banjac, N. Milošević, J. Ćurčić, D. Marjanović, N. Todorović, J. Krmar, Sanja Podunavac-Kuzmanović, N. Banjac, G. Ušćumlić, Comparative chemometric and quantitative structure-retention relationship analysis of anisotropic lipophilicity of 1-arylsuccinimide derivatives determined in high-performance thin-layer chromatography system with aprotic solvents, J. Chrom. A. 1628 (2020) 461439.

[10] K. Ciura, S. Dziomba, S. Nowakowska, M. Markuszewski, Thin layer chromatography in drug discovery process, J. Chrom. A. 1520 (2017) 9-22.

[11] R. Kaliszan, QSRR: quantitative structure-(Chromatographic) retention relationships, Chem. Rev. 107 (2007) 3212-3246.

[12] K. Héberger, Sum of ranking differences compares methods or models fairly, Trends Anal. Chem. 29 (2010) 101-109.

[13] N. Janković, Z. Bugarčić, S. Marković, Double catalytic effect of $\left(\mathrm{PhNH}_{3}\right)_{2} \mathrm{CuCl}_{4}$ in a novel, highly efficient synthesis of 2-oxo and thioxo-1,2,3,4-tetrahydropyrimidines, J. Serbian Chem. Soc. 80 (5) (2015) 595-604.

[14] J. Muškinja, N. Janković, Z. Ratković, G. Bogdanović, Z. Bugarčić, Vanillic aldehydes for the one-pot synthesis of novel 2-oxo-1,2,3,4-tetrahydropyrimidines, Mol. Divers. 20 (2016) 591-604.

[15] N. Janković, J. Trifunović Ristovski, M. Vraneš, A. Tot, J. Petronijević, N. Joksimović, T. Stanojković, M. Đorđić Crnogorac, N. Petrović, I. Boljević, I.Z. Matić, G.A. Bogdanović, M. Mikov, Z. Bugarčić, Discovery of the Biginelli hybrids as novel caspase- 9 activators in apoptotic machines: lipophilicity, molecular docking study, influence on angiogenesis gene and miR-21 expression levels, Bioorg. Chem. 86 (2019) 569-582.

[16] J. Ristovski Trifunović, Ž. Žižak, S. Markovićc, N. Janković, N. Ignjatović, Chitosan nanobeads loaded with Biginelli hybrids as cell-selective toxicity systems with a homogeneous distribution of the cell cycle in cancer treatment, RSC Adv 10 (2020) 41542-41550.

[17] N. Janković, S. Stefanović, J. Petronijević, N. Joksimović, S.B. Novaković, G.A. Bogdanović, J. Muškinja, M. Vraneš, Z. Ratković, Z. Bugarčić, Water-tuned tautomer-selective tandem synthesis of the 5,6-Dihydropyrimidin-4(3H)-ones, driven under the umbrella of sustainable chemistry, ACS Sustain. Chem. Eng. 6 (2018) 13358-13366.

[18] M. Đorđić Crnogorac, I.Z. Matić, A. Damjanović, N. Janković, A. Krivokuća, T. Stanojković, 3D HeLa spheroids as a model for investigating the anticancer activity of Biginelli-hybrids, Chem. Biol. Interact. 345 (2021) 109565.

[19] E. Soczewinski, C.A. Wachtmeister, The relation between the composition of certain ternary two-phase solvent systems and RM values, J. Chromatogr. 7 (1962) 311-320.

[20] T. Mosmann, Rapid colorimetric assay for cellular growth and survival: application to proliferation and cytotoxicity assays, J. Immun. Methods 65 (1983) 55-63.

[21] K. Héberger, K. Kollár-Hunek, Sum of ranking differences for method discrimination and its validation: comparison of ranks with random numbers, J. Chemom. 25 (2011) 151-158.

[22] K. Kowalski, On the predictive performance of biased regression methods and multiple linear regression, Chemom. Intell. Lab. Syst. 9 (1990) 177-184.

[23] J.G. Topliss, R.J. Costello, Chance correlation in structure-activity studies using multiple regression analysis, J. Med. Chem. 15 (1972) 1066-1068. 